This item was submitted to Loughborough's Research Repository by the author.

Items in Figshare are protected by copyright, with all rights reserved, unless otherwise indicated.

\title{
Urban landscape and spatial heritage: the case of gateway-pathways in Zagreb, Croatia
}

\section{PLEASE CITE THE PUBLISHED VERSION}

https://doi.org/10.1080/17567505.2018.1514568

\section{PUBLISHER}

(c) Taylor \& Francis

\section{VERSION}

AM (Accepted Manuscript)

\section{PUBLISHER STATEMENT}

This is an Accepted Manuscript of an article published by Taylor \& Francis in The Historic Environment: Policy \& Practice on 12 October 2018, available online:

http://www.tandfonline.com/10.1080/17567505.2018.1514568.

\section{LICENCE}

CC BY-NC-ND 4.0

\section{REPOSITORY RECORD}

Zaninovic, Tamara, Falli Palaiologou, Sam Griffiths, and Bojana Bojanic Obad Scitaroci. 2018. "Urban Landscape and Spatial Heritage: The Case of Gateway-pathways in Zagreb, Croatia". figshare. https://hdl.handle.net/2134/34567. 


\title{
Urban Landscape and Spatial Heritage: the Case of Gateway- Pathways in Zagreb, Croatia
}

[Accepted Manuscript]

\section{Tamara Zaninovića* Garyfalia Palaiologou ${ }^{\mathrm{b}}$ Sam Griffiths ${ }^{\mathrm{c}}$ Bojana Bojanić Obad Šćitarocia ${ }^{a}$}

\author{
${ }^{a}$ Department for Urban and Spatial Planning and Landscape Architecture, University \\ of Zagreb - Faculty of Architecture, Zagreb, Croatia; \\ ${ }^{b}$ School of Architecture, Building and Civil Engineering, Loughborough University, \\ Loughborough, Leics, UK; \\ ${ }^{c}$ Bartlett School of Architecture, University College London, UK. \\ *tmaric@arhitekt.hr
}

Short biographical notes (200 words max)

Tamara Zaninović, M.Arch. (born Marić in 1986) is a research and teaching assistant at the Department of Urban Planning, Spatial Planning and Landscape Architecture at the Faculty of Architecture, the University of Zagreb where her research is a part the project 'Heritage Urbanism' (HERU HRZZ 2032). She is a PhD Student at Vienna Technical University (TU Wien), supervisors: prof. Richard Stiles, PhD (TU Wien) and prof. Bojana Bojanić Obad Šćitaroci, $\mathrm{PhD}$ (Univ. of Zagreb). She was a guest $\mathrm{PhD}$ student in London in 2016 at the Space Syntax Laboratory, the Bartlett School of Architecture, UCL, supervisors: Sam Griffiths, PhD and Garyfalia Palaiologou, PhD. Area of research: urban landscape, streets, heritage, walkspaces and space syntax. tmaric@arhitekt.hr

Garyfalia (Falli) Palaiologou is a Lecturer in Architecture and Urban Studies at Loughborough University, UK. Earlier she was Research Fellow at the UCL Bartlett School of Architecture at the Space Syntax Laboratory, funded by the Engineering and Physical Sciences Research Council (EPSRC). She holds a PhD in Architectural and Urban Morphology, and a Master's in Advanced Architectural Studies from UCL. Her PhD research investigated the 20th century urban transformation of London terraced houses and Manhattan row houses, focusing on street micromorphology and street liveability. Her post-doctoral research looked at the use of 
space syntax methods in delimitation practices for UNESCO historic urban landscapes. In 2017, she organized the Historic Urban Landscape Forum (hulforum.org) networking initiative, under UNESCO patronage. ORCiD: https://orcid.org/0000-0002-2000-1081; twitter: @falli_p

Sam Griffiths studied history at the University of Sheffield and took his doctorate at UCL's Bartlett Faculty of the Built Environment. He is Associate Professor in the Space Syntax Laboratory at the Bartlett School of Architecture. His research is highly interdisciplinary bringing formal spatial morphological methods to questions in urban social history, and historical perspectives to questions of urban design. Recent publications include an edited collection for Routledge Spatial Cultures: towards a new social morphology of cities (2016). He has published widely on the spatial culture of Victorian Sheffield and suburban high streets. He is currently working on a book for Routlege look at the role of architecture in conceiving and writing the urban past.

Prof. Bojana Bojanić Obad Šćitaroci, is a graduate architect and has a PhD in the field of architecture and town planning. She is a professor at the Faculty of Architecture of the University of Zagreb and the Head of the Department of town-planning, spatial planning and landscape architecture. Her teaching subjects are: landscape architecture and town-planning at undergraduate, graduate and doctoral studies. She is author/co-author of scientific books, scientific articles, scientific studies from the field of traditional architecture, landscape architecture, town-plans and studies and designs from the field of garden and landscape architecture. She is a scientific-researcher at European project "Smart U Green" and Croatian research project "Heritage Urbanism”. She is a reviewer of scientific-research projects in the field of architecture and town planning. She has taken part at numerous national and international scientific-expert conferences with topics in the field of protection of traditional architecture, cultural heritage and landscape architecture. http://scitaroci.hr/ ; bbojanic@arhitekt.hr 


\title{
Urban Landscape and Spatial Heritage: the Case of Gateway- Pathways in Zagreb, Croatia
}

\begin{abstract}
The paper examines theoretical and analytical premises for developing a systematic characterisation of spatial heritage in the urban landscape. Spatial heritage is proposed as alternative and active link between material and immaterial agencies in the formation of the cultural landscape over time. We probe the application of interdisciplinary research at the interface of spatial history, urban heritage, and space syntax studies to expand heritage definitions and understand the role of diachronic spatial elements in urban sustainability. With the use of space syntax analytical methods, we test quantitative descriptions of typological definition of 'gateway-pathways' in the urban landscape. The term refers to routes that historically connected peripheral settlements to the urban core of contemporary cities. The typology was developed during on-going research by the first author at the University of Zagreb as a part of Heritage Urbanism project with reference to a sample of 18 Central European cities that were formerly provincial capital cities of the Austro-Hungarian monarchy. This paper looks at the city of Zagreb, Croatia and assesses its historic pathway typologies via syntactical analysis using the transect method established by Hillier (1999). Results give a quantitative validation of the spatial significance of some historical urban pathways over others.
\end{abstract}

Keywords: gateway-pathways; space syntax; cultural heritage; urban streets; Zagreb; Croatia

\section{Introduction}

Growing interest in the development of inclusive and integrative approaches to the management of cities suggest the need for theories and methodologies that consider active interdependencies between tangible and intangible layers of the extended urban context. The idea of urban landscapes acknowledges not only the fast-changing nature of cities' physical boundaries and their demand in resources; but also, the complexities associated with processes of urban formation, and the interlinked side-effects of environmental and humanitarian crises. Against this background of increasing 
uncertainty for urban futures, scholars and practitioners are revisiting the role of heritage in response to the challenge of sustainability, recognised as a cultural problem inasmuch as it is a cultural choice (Rodwell, 2003; Tweed \& Sutherland, 2007). Questions on which actions to prioritise in the urban landscape and which of its assets to sustain become pressing issues and largely depend on our assessment of what we value (Pendlebury, 2013; Fredheim \& Khalaf, 2016). In this sense, urban sustainability is linked to definitions of and decisions about heritage to a much greater extent than is currently acknowledged by the sustainability agenda (Guzmán, et al., 2017).

In this paper, we focus on the understudied case of ordinary urban space as urban heritage and driver of spatial sustainability in the urban landscape. We put forward the idea of spatial heritage as an alternative type of heritage. The research derives from the Heritage Urbanism project, developed at the Faculty of Architecture, the University of Zagreb. ${ }^{1}$ The city of Zagreb is one of the cities analysed by the Heritage Urbanism project and is the principal case study presented in this paper. We advance theory, methods and tools of analysis from the field of space syntax research to: a) demonstrate how space, seen as a cultural entity in urbanisation processes, is relevant to urban heritage discourses, and b) propose new trajectories for interdisciplinary research at the interface of spatial history, urban heritage and space syntax in order to better inform sustainability practices.

The urban landscape of Zagreb is a cultural landscape analysed in terms of its spatial heritage. Taylor and Lennon highlight how cultural landscape 'is an approach with an intellectual basis not just in history but also one with a temporal and spatial

\footnotetext{
${ }^{1}$ Specifically, it draws on research undertaken by the first author on the project sub-theme of street heritage in Central European context.
} 
perspective’ (Taylor \& Lennon, 2011: 538). Space syntax analysis considers local topological and geometrical conditions to give quantitative description to configurational (i.e. relational) aspects of spatial structures. As such, syntactic descriptions are both place-specific and urban system-specific and provide a means for comparative understanding of spatial processes in urban landscapes. Empirical and historical research in the field consolidates the prescriptive and hermeneutic potential of syntactic inference for the study of the physical city as generative of the social city (Hillier \& Vaughan, 2007).

By adopting a spatial and temporal perspective we assume a process-driven appreciation of heritage, rather than a static, object-driven approach. To this end, the paper introduces a specific typology of urban pathways 'historical gateway pathways' and examines urban transformation processes along historical routes to assess the importance of these streets in the urban landscape of the contemporary city configuration. The historical gateway-pathways in Zagreb have kept their distinctiveness to different extents, depending on how they were located in relation to the subsequent development of infrastructure. The methodological development undertaken for this paper concerns identifying the extent to which syntactical measurements (i.e. quantitative descriptions of urban street network configuration) can be used to describe these typological differences, thereby enabling researchers to better understand the definition of 'gateway-pathways' as a distinct dimension of spatial heritage. Results confirm a quantitative validation of the spatial significance of some historical urban pathways over others.

\section{Spatial history and spatial heritage in the urban landscape}

'Spatial culture' is a term introduced by Hillier (1989) to emphasise how spatial arrangements do not only embody cultural meaning by reflecting the ways societies are 
organised in space but also the fact that they contribute in the generative processes of cultural formation by distributing potential human encounters in space. Hillier (1996) goes on to propose an active and mutually formative relation between physical space and society: physical space generates over time complex 'multiplier effects' (ibid.: 12527) that have an impact on spatial arrangements and in turn on the social production and re-production of urban life in space. Hillier's argument considers an active linkage between the material and immaterial components of human settlements (Harvey, 1973; Hillier \& Leaman, 1973; Lefebvre, 1991). Adopting this viewpoint, we note that diachronic understanding of the space-society relation is key to the identification of the production of culture in space and through space. Whereas culture in space has been the traditional subject of urban history and heritage studies, the way cultural production is co-generated by space has been a less prominent theme within these fields (Griffiths, 2009).

This imbalance brings with it the danger of oversimplification of the contribution of the built environment to culture by seeing the human settlement as cultural object due only to its tangible characteristics (i.e. aesthetic/visual/material/architectural value) and/or their symbolic cultural meaning (i.e. cultural/historic symbolism/identity meanings) (Tweed \& Sutherland, 2007). It excludes notions of alternative heritages (Smith, 2006) that arise from the diachronic and informal role of space as temporal lived place (see Harvey, 2001; Taylor, 2009). It also promotes a static view of tangible heritage seeing it as a quality that needs to be preserved intact, rather than thinking of 'heritage as emergent process' (Harvey, 2001). For example, Psarra (2010) explains how the study of historical processes enables the identification of cultural emergence in architecture and of the formative processes/historical incidents that have generated this. By studying spatio-temporal 
cultural production and re-production, it becomes possible to investigate the potential interdependencies of spatial and cultural sustainability. The difference between spatial and cultural sustainability is on the focus. In spatial sustainability the focus is on geometric and configurational spatial ordering in the city (Hillier, 2009) while in cultural sustainability the focus is on cultural elements, practices and heritage (Soini \& Birkenland, 2014).

In this paper, we propose that the study of spatial history can contribute to redefinition of heritage values (e.g. Tunbridge, 1984; Lennon, 2006; Pendlebury, 2013; Torre, 2013) by embracing a dynamic view of the urban landscape. The study of the evolution of spatial cultures over time, which is a subject of spatial history, offers insights into the diachronic properties of spatial systems and their relation to both ephemeral and persisting dimensions of culture. A core component of the spatial structure of the urban landscape is the street network. Streets hold a prominent role in supporting, enabling and even, generating urban life (Jacobs, 1961; Whyte, 1980; Gehl, 2010; Thomas, 2016) and cultural activity (Jacobs, 1993; Griffiths, 2016).

The consideration of streets as backbones of the spatial structure of urban landscapes is strongly put forward by space syntax theory. Space syntax theory (Hillier \& Hanson, 1984; Hillier, 1996) offers a theoretical basis as well as analytical tools for the study of spatial configuration - namely, of the way spaces within an urban spatial system relate to all other spaces within this system (Hillier, 1996: 20-23). Spatial configuration is by mathematical definition a relativistic concept based on graph theory (Hillier \& Hanson, 1984: 14, 147), therefore specifically rejects approaches focussed on individual spaces, fragmented areas or ensembles. The syntactic study of the diachronic continuities of spatial configurations reveal persistent spatial structures by identifying historically prominent streets, both spatially (in terms of connectivity and accessibility) 
and morphologically (in terms of geometric and topological characteristics). The physical distinctiveness is observed to align with distinct cultural and socio-economic character. Such an example is the 'high street' phenomenon typically of UK urban settlements (Griffiths, 2015). Griffiths makes a case for the high street being a 'morphological event' that maintains a cultural and socio-economic prominence within its local surroundings over time and under a succession of contrasting socio-economic contexts. By shedding light on diachronic spatial structures, space syntax opens the way for the acknowledgement of an alternative type of urban heritage - that is spatial heritage.

Spatial heritage, revealed through the study of spatial history, is a timely concept in heritage discourse. By being cultural product of spatial configuration, spatial heritage permeates the urban landscape - both as a contemporary (or synchronic) agent of the urban life as well as an inherent feature of the historical urban landscape, evolving over time and across physical scales (Griffiths \& von Lünen, 2016). Urban landscape is a sub-category of the cultural landscape (Schlüter, 1899) - the latter being a concept that encouraged inclusive definitions of heritage towards the acknowledgement of the culture-nature interdependence (see Taylor 2009 for an overview). Cultural landscapes as heritage sites are named in UNESCO World Heritage management processes since 1993 (Taylor \& Lennon, 2011). It follows that the significance of a landscape-integrated approach to urban conservation is not news in heritage discourses (Harvey \& Waterton, 2015). Seeds of this idea are evident in the 2005 Vienna Memorandum (Article 7), which then grew to become a new operational guidance for practice in World Heritage sites of urban character: the 2011 Recommendation on the Historic Urban Landscape by UNESCO (Bandarin \& van Oers 2012; 2014) outlines an initiative to establish this shift to a more connected view of the various phases of urban development. 
The historic urban landscape is defined in the Recommendation text as a spatial category of urban area which, according to definition paragraphs ${ }^{2}$, includes sites, built environments, infrastructure, lands use patterns and spatial organisation, perceptions and visual relationships. Only 'Knowledge and planning tools', out of four categories of tools in the historic urban landscape approach, directly propose methods for spatial assessment as documentation, mapping and impact assessments. We argue, therefore, that spatial configuration, i.e. street networks, as an active agent of the urban landscape and of urbanism in general is still underrepresented in the Recommendation text. Subsequently, knowledge about existing methods and tools to study space as an historical cultural entity - such as space syntax historical research (see Palaiologou \& Griffiths, 2019; also in Griffiths, 2009) - receives limited exposure, which acts as an impediment for interdisciplinary development and application (Griffiths, 2012).

Interdisciplinary exchanges as well as dialogue between academic research and policy (Veldpaus, et al., 2013) remain topical challenges for delivering Goal 11 (specifically, target 11.4) from the United Nations 2030 Agenda for Sustainable Development. The multifaceted role of cultural heritage in this collective effort needs to be reconsidered to achieve greater integration between culture and other dimensions of sustainability (Rodwell, 2003; Guzmán, et al. 2017). The study of spatial history to identify spatial heritages falls within this wider effort to acknowledge the role of culture in the sustainability agenda. A step forward in this direction is to acknowledge spatial

\footnotetext{
${ }^{2}$ Page 3 in the 'Recommendation on the Historic Urban Landscape' by United Nations Educational, Scientific and Cultural Organization from Paris, 10 November 2011 <https://whc.unesco.org/uploads/activities/documents/activity-638-98.pdf> [Accessed: 24 July 2018]
} 
culture as on-going driver for sustainability. Specifically, in this paper we look at the role of spatial heritage, considered a subcategory of spatial culture, as a diachronic driver of spatial sustainability. To explore this proposition, we analyse specific streets in the urban structure which developed out of the historical pathway network.

\section{Historical routes as spatial heritage - defining 'gateway-pathways'}

This paper further elaborates preliminary results presented on the 11th Space Syntax Symposium (Marić et.al., 2017) to consider their significance in the wider context of research on spatial history and heritage. The concept, name and definition of 'gatewaypathway' was developed through initial case-study research of historical routes in 18 Central European cities from the perspective of urban heritage. The selected cities are formerly main provincial cities of the Austro-Hungarian monarchy: Vienna, Budapest, Prague, Ljubljana, Zagreb, Sarajevo (which are also state capitals in the 21st century), Lavov, Brno, Graz, Chernovitzi, Trieste, Linz, Salzburg, Innsbruck, Klagenfurt, Zadar, Opava, and Bregenz. The research examined historical maps composed under the Habsburg rule (Biszak, et al., 2014). These maps are the product of military surveys that capture the territory of the Austro-Hungarian monarch by using the same technique over

three historical periods: 1763-1787, 1806-1869 and 1869-1887 (Figure 1). The notion of 'historical gateway-pathways' refer to those routes that lead, or used to lead, into the historical urban core of a settlement (Marić \& Jakšić, 2011; Marić, et al., 2014). The significance of these routes in urban formation processes during the growth of cities strongly recommends a need for their terminological distinction from other routes.

To recognize the unique spatial role of gateway-pathways within the urban landscape, it is important to explore their spatial history and refer to their historical function within the street network. The identification of gateway-pathways involves examining changes in the relation between the urban historical centre and peripheral 
areas of the city. The focus is on tracing urban tissue transformations of the coreperiphery connecting routes. As such, inherent in the definition of gateway-pathways and their typological classification is a relational and diachronic understanding of urban transformations that extends beyond the often arbitrary boundaries of urban governance. Transformation processes include changes from trail to road and urban street, and finally to regional roads which are part of the wider urban landscape and connect public places from the city centre to periphery.
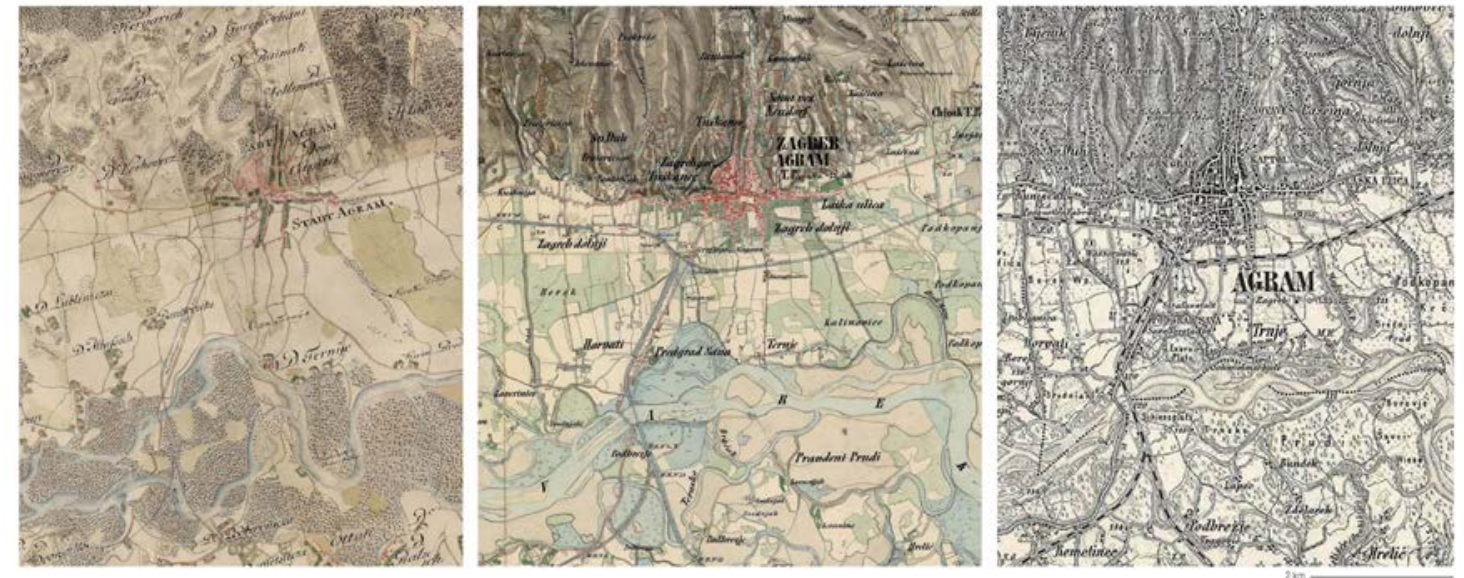

Figure 1. The city of Zagreb at the end on the 18th, the first half of the 19th and the second half of the 19th century on Habsburg military survey maps from online maps https://mapire.eu/en [Accessed: 21 November 2016.] (Biszak, et al., 2014).

Comparative examination of the historical military survey maps for Central European cities resulted in the initial historical identification of gateway-pathway typologies as qualitative combinations of: a) 'regional' or 'local' routes depending on the peripheral connections, and b) 'direct' or 'indirect' and/or 'transit' routes depending on how they connect with the historical urban core (i.e. settlement historical centre). In the typological classification of gateway-pathways, dominant categories are 'regional direct gateway-pathways' that connect the walled historic city with other towns and settlements. The case study of Zagreb is a particular example because its direct 
gateway-pathways are rare and only local in character since the historical walled settlements are located on hills. This category is 'local direct gateway-pathways' connecting the walled historic city with slopes towards the mountains. Indirect gateway-pathways lead to the extended historical core of the city, beyond the designated historic areas and/or walled town. They are at the very connection with the settlement often branched or connected to another gateway-pathway route. Transit gatewaypathways are characterised with linearity that can be detected as the route passing through the settlement, therefore, it can be both direct or indirect and local or regional. The typologies reflect differences in the spatial function each category has had throughout the process of the historical formation of the urban landscape.

The formation of the urban landscape as a cultural landscape is a physical and spatial process inasmuch as it is a cultural process in the conventional sense (Taylor, 2009: 14). Griffiths (2012) theorises the need for spatial descriptions to be understood within historical processes of cultural formation and vice versa. In his study of the spatial histories of Sheffield during the eighteenth and nineteenth centuries, Griffiths (2009) measures the spatial and functional continuity of prominent rural streets, since their regional origins and until their urban transformation. His analysis contradicts normative interpretations of the urban forces wearing down the rural character; instead, the author observes an evolutionary process from rural to urban identity. In the case of Sheffield, the study of spatial history enables an alternative assessment of heritage assets that takes into account inherent formative process (i.e. emerging from spatial structure itself) of the urban landscape seen as cultural object. It extends beyond fragmented approaches that detach urban places from their wider contemporary and historical material and immaterial contexts. Similarly, the spatial roles of gatewaypathways identified by the typologies mentioned earlier are associated with varying 
roles in terms of their cultural function in the wider tangible and intangible landscape over time. Whereas in this paper, the focus is to identify the spatial characteristics of gateway-pathways, potential future research will investigate further their roles in supporting cultural-cultural and/or cultural-natural landscape exchanges over time.

Building on Marić et al., (2017), the analysis presented here outlines a potential method for the quantitative characterisation of gateway-pathways as spatial heritage. It should be clarified that this method offers a mathematical validation; the qualitative dimensions of spatial heritage are considered in the conceptualisation of gatewaypathways, and further research on the subject is needed to examine the specific nature of quantitative-qualitative interdependencies.

\section{Gateway-pathways through the lens of syntactic inference}

Griffiths (2012) classifies the use of space syntax methods and analytical tools in the study of spatial history. His review picks up on important evidence that showcases the usefulness of syntactic inference in revealing interrelations of space and space function during urban formation processes. Specifically, for the study of spatial histories of streets, syntactic knowledge identifies dynamic processes that identify the street as an adaptable entity within the evolving urban landscape (Vaughan, et al., 2013; Törmä, et al., 2017). Palaiologou and Griffiths (2018) suggest how the study of historical processes on the balance between spatial continuity and change can reveal the 'heritage syntax' of urban streets. This paper is a contribution to this emerging research agenda, using syntactic inference to examine the spatial signature of heritage gateway-pathways.

Since its formation in late 1970s, the space syntax research field has developed a large set of urban case studies that allows for a comparative understanding of commonalities (i.e. generic characteristics) across the spatial configurations of urban landscapes. In explaining 'centrality as a process', Hillier (1999) identifies a generic 
characteristic that refers to the overall spatial structure of cities: a pattern of 'grid deformation' along the main routes and off the main routes. In terms of their geometry within the urban tissue, main routes are continuous long features and their axial lines have little angular deviation. The deformation occurs as local grid conditions adapt over time and the grid becomes denser with smaller scale urban blocks alongside and off those longer connectors. Gateway-pathway relates to 'centrality as a process' (ibid.) because it refers to those pathways that are continuous or near-continuous main routes and which are persistent over time, and hence relate to the core spatial structure. In spatial syntax terms, gateway-pathways are generic features of Hillier’s ‘deformed wheel’ concept (Hillier, 1996: 339-345; Hillier, 1999): they form part of the linearshaped street network that links the integrated (i.e. well-connected within the entire street network configuration) urban core to the segregated (i.e. less well-connected) urban periphery. This linear backbone is historically persistent, and it maintains radial connections from the expanding city edge towards the historical urban core. This syntactic description of the formative processes of the core spatial structure within the urban landscape offers the potential for a mathematical testing of the typological classification of gateway-pathways.

In this paper we bring spatial-morphological descriptions to the role of gatewaypathways in the urban landscape. In the next sections we develop a comparative study of the spatial profile of Zagreb to provide context for the subsequent focus on the syntax of four historical gateway-pathways, adapting Hillier's transect method.

\section{The spatial syntax of Zagreb}

Zagreb has a distinct topology because of its location on the hills between the mountain of Medvednica and the River Sava (Figures 1-3). The urban landscape is characterised by a bi-nucleated urban core that was formed by the merging of two walled historical 
settlements and the main square of the newly formed city sits outside them. By the 1850s, houses had started to gather along the main gateway-pathway routes which lead to main square beneath the two hills with medieval settlements. During a phase of rapid growth in the second half of the 20th century, the main urban area extended to include surrounding village settlements. With a series of architectural and master planning competitions, the municipal authority of Zagreb planned new entry routes and axes to the city that passed through areas without presence of historical pathway networks. (Milić, 1995: 100; Milić, 2002: 350; Jukić, 1997; Marić, et al., 2017) Nevertheless, the historical gateway-pathways remain distinct urban elements in the city layout compared to later infrastructural developments of railway and motorway transport networks.

Gradec and Kaptol, the medieval centres of the two historical settlements (Figures 2 and 3) were walled and located at a distance of $2.8 \mathrm{~km}$ from the River Sava, on the slopes of Medvednica mountain. The exact traces of the Roman roads that passed through Zagreb’s urban landscape have not yet been precisely identified. There are indications of a southern connection from the east to the Roman town Siscia (now the town of Sisak), and possibly an east-west connection with Roman municipium and Sava River port called Andautonia (now an archaeological site in the settlement Šćitarjevo, $20 \mathrm{~km}$ from Zagreb) that probably also used to be a regional gateway-pathway besides the known Poetovium-Siscia (Ptuj-Sisak) north-south connection. Since the Zagreb urban landscape was (a) developed later in history after the antique period, (b) distanced from the antique port and (c) considering the difficulties of mapping the geo-locations of ancient historical pathways, the typological identification was conducted based on high quality military surveys from the 18th to beginning of 20th century just before the rapid urban growth when still historical layers could be traced on these maps. For Zagreb, trails of the original gateway-pathways as well as building footprints outlining 
the historical urban core are visible from the first military survey mapped in 1783-84

(Figure 2). Typological classification was first performed independently of the analysis of the syntactical model of Zagreb. Subsequently, to test the method of syntactic inference in detecting historical gateway-pathway typologies, a contemporary syntactic model was created. The aim was to determine how far space syntax analysis of the spatial configuration of contemporary urban landscapes can detect historical routes that have undergone transformation processes.

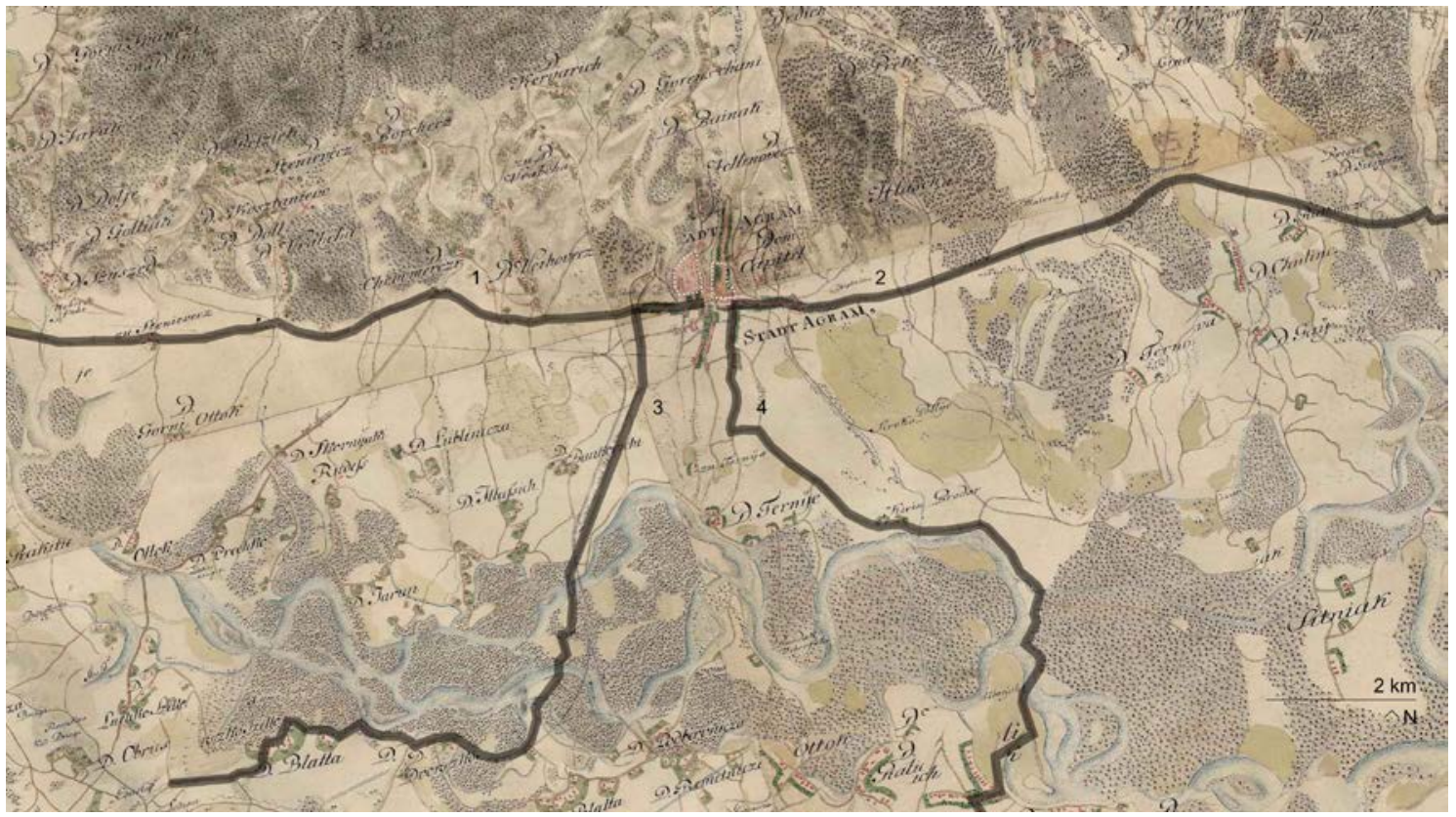

Figure 2. The city of Zagreb - first military survey map with marked identification of ‘indirect gateway-pathways’ by numbers $1=$ =Ilica, $2=$ Vlaska, 3=Savska and $4=$ Petrinjska and dashed-white area of historical core: Gradec (west) and Kaptol (east) settlement.

\section{The axial model}

Croatia has 21 counties, with Zagreb being one of them. The administrative boundaries are not equivalent to the built-up area of the city and extend beyond the urban landscape. Two main criteria were considered in defining the size of the syntax model: 
1) the geography of the wider landscape and the natural topographical boundaries: the mountain to the north and river to the west and south-east, and 2) 'hard' artificial infrastructural boundaries, including the detour motorway to the south and east. The basemap of the syntactical model is approximately 20x10 km in layout size, which is an area equivalent in approximation to the Zagreb Master plan ${ }^{3}$ (Mrak-Taritaš, 2008: 232).

The axial model is a map of the spatial configuration of a network of streets and open spaces that is comprised of the longest and fewest straight lines of sight and physical accessibility (called 'axial lines’) that cover this network (Hillier \& Hanson, 1984: 91-92; Penn, 2003). It was drawn in ArcMap software using as background information GIS data layers of buildings and transportation network geodata provided by the city municipality of Zagreb ${ }^{4}$. An Orthophoto Map from 2012 was used as the basis, cross-referenced with the layer of vectorised and georeferenced buildings. The model includes all main urban public spaces such as streets, squares, and parks. The latter were mapped according to a layer of GIS data on pedestrian traffic, combined with data from terrain experience and the OpenStreetMap ArcMap base layer. Three large-scale urban parks ${ }^{5}$ are excluded from the map because they are bounded pedestrian subsystems (without public access throughout the whole day) and show stark differences in scale when compared to the freely accessible street network of the

${ }^{3}<$ https://www.zagreb.hr/odluka-o-donosenju-generalnoga-urbanistickog-plana/89158>

[Accessed: 24 ${ }^{\text {th }}$ July 2018]

${ }^{4}$ City Office for the Strategic Planning and Development of the City / Gradski ured za strategijsko planiranje i razvoj Grada, Sektor za strategijske informacije i istrazivanja

${ }^{5}$ These are: Maksimir park, with the zoo area; Bundek park near River Sava, with the lake and the hippodrome area; and finally, Jarun park area which is the main recreational area of the city. 
surrounding city. The Banks of River Sava, including its embankment system, were mapped as one of the main pedestrian recreation areas and by that criterion, the main road in around Jarun area was also added. When passages and block entrances lead to public buildings inside the $19^{\text {th }}$-century block areas, then these are mapped as well with the $19^{\text {th }}$-century grid street pattern. At the northern part of the urban landscape, the city meets with Medvednica slopes and east-west connections in that areas are formed via various stairs. The steps were modelled as broken axial lines, which increases the spatial depth of the syntax model (number of directional steps from one axial line to another) in order to consider the vertical height difference and its impact on visual and physical accessibility.

\section{Analysis of syntactic profile}

The body of space syntax research on central European cities is very limited. ${ }^{6}$ One of the most analysed cities through space syntax methodologies is London, UK. To have a comparative understanding for the syntactic profile of Zagreb the main figures for geometric descriptions and space syntax measures at different scales of analysis for Zagreb are considered against the equivalent results for Greater London (Table 1). The city area of Zagreb is almost two and a half times smaller in scale than London $\left(641 \mathrm{~km}^{2}\right.$ Zagreb and 1,572 $\mathrm{km}^{2}$ London area). London has more than a ten times larger population figures (790,017 people in Zagreb; 8,673,713 in London) and is 4.5 times denser (1,232 people per $\mathrm{km}^{2}$ for Zagreb; 5,518 per $\mathrm{km}^{2}$ for London). In terms of syntactic models, the

\footnotetext{
${ }^{6}$ Dino et al. (2015; 2016; 2017) analyse urban transformations of Tirana (Albania) in terms of urban morphology by looking at built form and street networks during two different political ruling and planning authorities. Shpuza (2009; 2014) gives detailed syntactic comparison of the spatial configurations of Adriatic and Ionian cities.
} 
spatial configuration in Zagreb is comprised of 7.5 times fewer axial lines than in London. Both models are drawn within the 'hard' boundary of the motorway. While the administrative borders of London are within the M25 area, Zagreb's administrative border, as mentioned earlier, is wider than the model size and the half-ring of the motorway system, and it includes large surfaces of natural and empty areas in between.

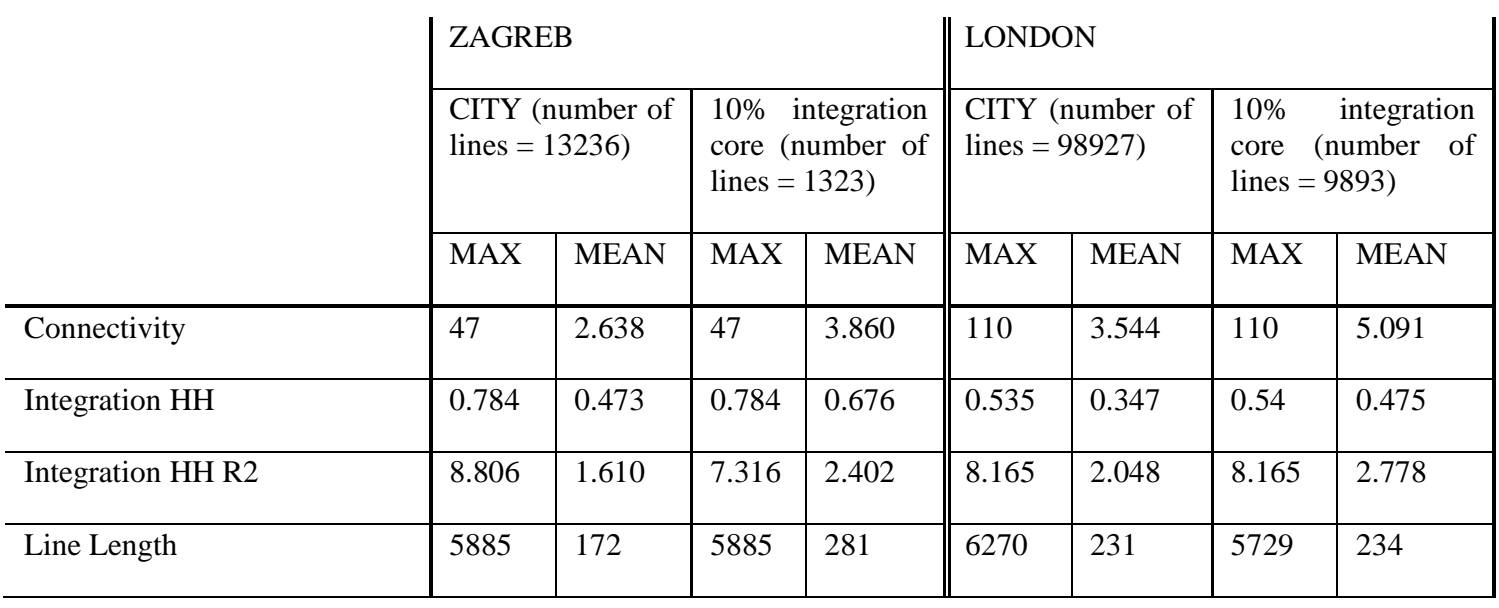

Table 1: Comparison of values from axial analysis for connectivity, integration and line length between Zagreb and London in the overall system and 10\% integration core. (C) Tamara Zaninović

Connectivity is a simple measure which shows the number of connections that each axial line has to other lines. Integration is a measure for 'the distance from each spatial element to all others in a system’ (Hillier, et al., 2012: 155) and it has been found to correlate with pedestrian to movement for spatial elements (Hillier \& Iida, 2005). Both measures are calculated in Depthmap software (Turner, 2001). In Table 1, we can see that London overall has higher connectivity both for the entire model and the $10 \%$ integration core - the latter being comprised of the axial lines with the $10 \%$ highest Integration-HH values calculated for the entire spatial configuration (radius catchment $\mathrm{R}=n$ ). Line length maximum and mean is larger for the entire system in London, but it is interesting that Zagreb has slightly longer lines in the $10 \%$ integration core. The 
situation is more complex for integration; Zagreb is found to have higher values when comparing the entire network (Integration-HH), while London appears to be more integrated locally (Integration-HH radius-2, calculated at a catchment of two axial steps away from each spatial element). The first observation is justified considering that London is a denser grid to Zagreb which means it has developed more spatial depth over time, while at the same time its spatial configuration has been found to enable the formation of integrated localities ('grid deformations' or 'urban villages', see Hillier, 1999; Hillier, et al., 2012: 155).

Zagreb's axial integration (Figure 4) shows that the two historical nuclei of Gradec and Kaptol (uptown) medieval settlements are not part of the top integration values or the $10 \%$ integration core. Instead, the $10 \%$ integration core of Zagreb is comprised of: the entire 19th century block structure (downtown); the central axis connecting the New Zagreb area across and south from River Sava with the areas along the Savska diagonal, and its complementary street on the east (Radnička road and Držićeva avenue). These diagonals and east-west connection streets are found in the $10 \%$ integration core, they are contemporary entrances or gateways from the periphery of the urban landscape to areas in the city centre. High integration does not permeate the medieval settlements due to their topological and geometrical features (denser grid, shorter lines, big angular turn from one line to another). Instead, subsequent street development links the growing surrounding city to the periphery of the medieval settlements. Topography and geometry justify why the $10 \%$ integration core does not include the medieval villages, whereas it includes contemporary gateway-pathways. 


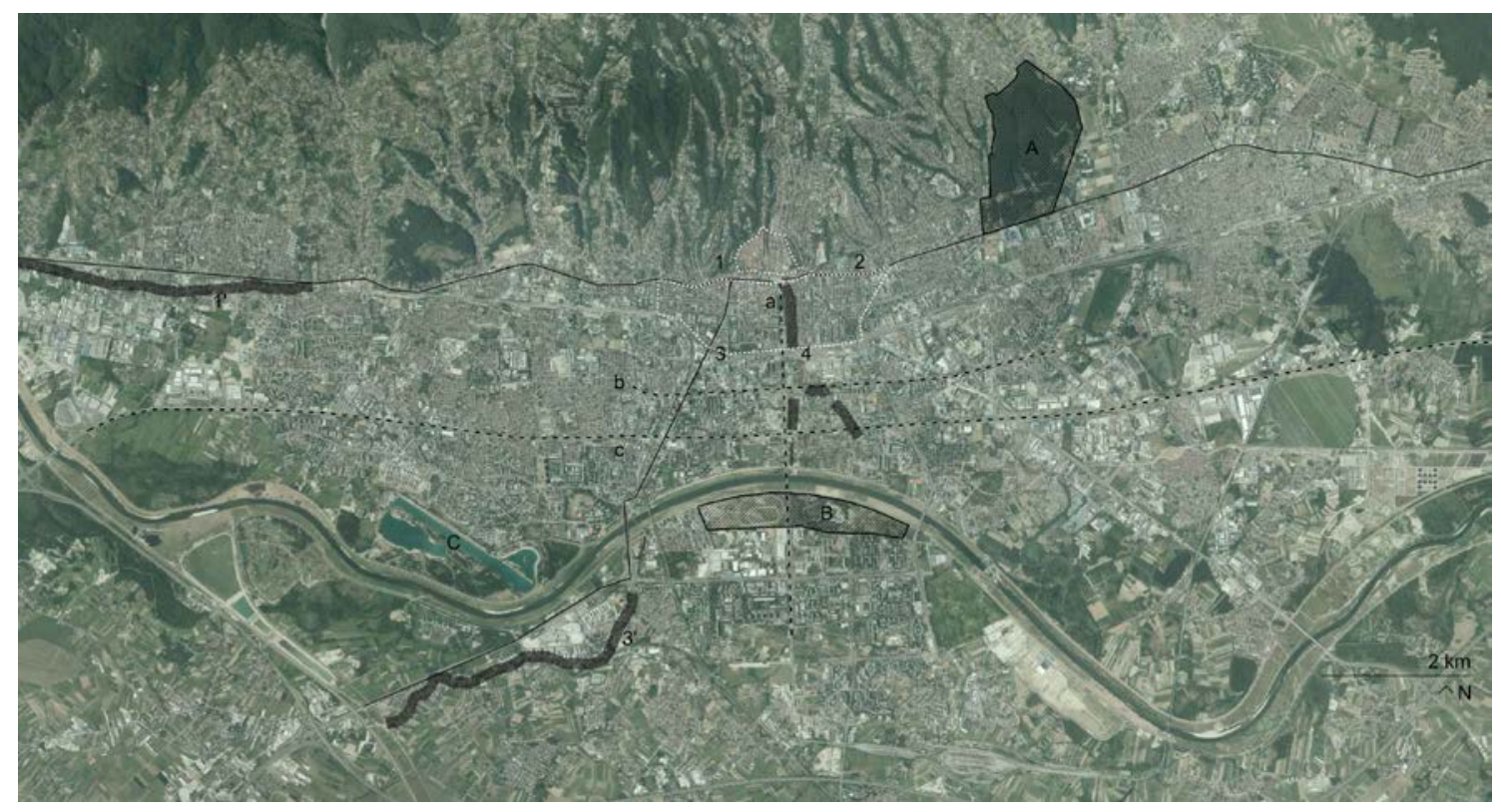

Figure 3. The city of Zagreb - 21st century aerial view with: 1=Ilica gateway contemporary, 1'=Ilica historical gateway-pathway route in contemporary urban form, 2=Vlaska gateway contemporary, 3=Savska gateway contemporary, 3’=Savska historical gateway-pathway route in contemporary urban form, 4= Petrinjska historical pathway traces in contemporary urban form; a=Zagreb central planned axis, b=Vukovarska street (modernistic street), c=Zagrebacka avenue (contemporary western gateway route to the city); $\mathrm{A}=$ Maksimir park, $\mathrm{B}=$ Bundek park and the hippodrome, $\mathrm{C}=$ Jarun recreational park and dashed-white area of Gradec and Kaptol (Up-town, north) and 19th century block planned structure (Down-town, south). Habsburg military survey maps from online maps https://mapire.eu/en [Accessed: 21 November 2016.] (Skalamera et al. 1994).

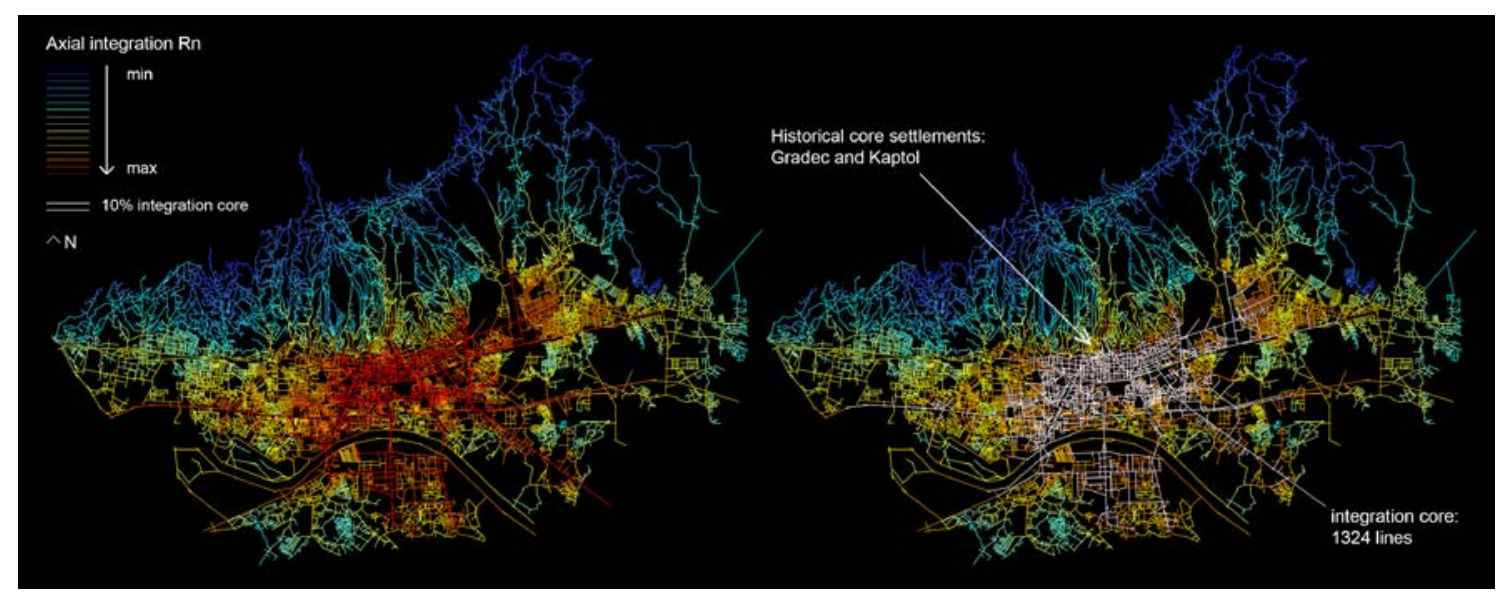

Figure 4. Zagreb axial integration Rn and marked in white lines $10 \%$ most integrated lines as integration core. (C) Tamara Zaninović 


\section{The syntax of gateway-pathways in Zagreb}

To understand urban growth processes in the city of Zagreb, we compared four historical gateway-pathways (Ilica, Vlaška, Savska and Petrinjska) to three new entry avenues to the city that were planned in the 20th century (Vukovarska, Central axis and Slavonska-Zagrebačka avenue). These later street network additions to the urban landscape are part of the $10 \%$ integration core (Figure 3).

The four historical gateway-pathways were identified through a selection process in ArcGIS by comparing the contemporary syntactical model to the georeferenced historical maps. Table 2 summarises axial lines measurements for historical and contemporary the gateway-pathways: maximum and mean values for integrationHH (i.e. calculated for the entire spatial configuration), integration HH R2 (i.e. calculated at radius $\mathrm{R}=2$ axial steps), connectivity, and line length. Table 2 also includes information on the number of axial lines that comprise each gateway-pathway and their total length. The first row shows numeric values for the entire system of Zagreb; remaining middle rows show the values for four historical gateway-pathways, and the last three rows show the values for three twentieth century avenues. Each historical gateway pathway is subdivided according to up three selection methods for axial lines (where applicable): (1) lines that form in the contemporary map (c.2012) today’s continuous extended pathways from the centre to the periphery - these are marked as 'cont.*' in Table 2; (2) lines that comprise the specific historical street in its contemporary length - named as 'st.' in Table 2; and finally, (3) remaining lines of the historical gateway-pathway from the first or second military survey maps, and which appear in the contemporary map. 


\begin{tabular}{|c|c|c|c|c|c|c|c|c|c|c|}
\hline & \multicolumn{2}{|c|}{$\begin{array}{l}\text { Integration } \\
\mathrm{HH}\end{array}$} & \multicolumn{2}{|c|}{$\begin{array}{l}\text { Integration } \\
\text { HH R2 }\end{array}$} & \multicolumn{2}{|c|}{ Connectivity } & \multicolumn{4}{|c|}{ Line lengths and number } \\
\hline & $\max$ & mean & $\max$ & mean & $\max$ & mean & $\max$ & mean & sum & $\mathrm{n}$ \\
\hline Zagreb & 0.784 & 0.473 & 8.806 & 1.610 & 47 & 2.637 & 5885 & 172 & 1 & 13236 \\
\hline \multicolumn{11}{|c|}{$\begin{array}{c}\text { Group 1: historical gateway-pathways of Zagreb } \\
\text { (selected remaining historical axial lines in the contemporary axial map) }\end{array}$} \\
\hline Ilica hist. & 0.709 & 0.556 & 4.942 & 2.923 & 18 & 6 & 1224 & 434 & 12598 & 29 \\
\hline Savska hist. & 0.778 & 0.560 & 6.743 & 2.304 & 47 & 5.560 & 2965 & 386 & 9646 & 25 \\
\hline Petrinjska hist. & 0.732 & 0.684 & 4.245 & 2.943 & 12 & 5.778 & 716 & 333 & 2997 & 9 \\
\hline Vlaška hist. and cont. & 0.713 & 0.638 & 5.393 & 3.687 & 23 & 8.563 & 3658 & 812 & 12995 & 16 \\
\hline \multicolumn{11}{|c|}{$\begin{array}{l}\text { Group 2: contemporary route of historical gateway-pathways which were redirected though historical development } \\
\text { and planning (selected axial lines along contemporary redirections of historical pathways) }\end{array}$} \\
\hline Ilica cont. & 0.709 & 0.602 & 4.942 & 3.170 & 18 & 6.789 & 3450 & 651 & 12375 & 19 \\
\hline Savska cont. & 0.78 & 0.70 & 6.74 & 3.45 & 47 & 11.833 & 3062 & 1161 & 9966 & 6 \\
\hline \multicolumn{11}{|c|}{$\begin{array}{l}\text { Group 3: contemporary urban streets at the route of historical gateway-pathways } \\
\text { (axial lines that comprise only part of historical gateway-pathways defined as urban streets) }\end{array}$} \\
\hline Savska st. & 0.778 & 1 & 6.743 & 1 & 47 & 1 & 2965 & l & 1 & 1 \\
\hline Petrinjska st. & 0.732 & 0.712 & 4.245 & 3.50 & 12 & 8 & 717 & 459 & 919 & 2 \\
\hline \multicolumn{11}{|c|}{ Group 4: $20^{\text {th }}$ century planned avenues } \\
\hline Vukovarska st. & 0.784 & 0.722 & 6.523 & 3.954 & 43 & 12.667 & 3883 & 1117 & 6699 & 6 \\
\hline Central axis & 0.753 & 0.716 & 5.327 & 3.625 & 21 & 8.429 & 4427 & 1024 & 7168 & 7 \\
\hline Zagrebačka av. & 0.767 & 0.674 & 4.570 & 3.239 & 13 & 6.429 & 3860 & 1670 & 23394 & 14 \\
\hline
\end{tabular}

Table 2: Comparing axial measurements from axial analysis in the city of Zagreb. (C) Tamara Zaninović

Table 2 enables multiple cross-comparisons. The first point for discussion is the syntax of gateway-pathways against the syntactic profile of the whole Zagreb spatial configuration. Both historical and twentieth century gateway-pathways show similar characteristics when compared to the whole urban network: maximum values of Integration-HH for gateway-pathways are very close or the same as the maximum values in the entire system (analysis calculated at radius $\mathrm{R}=n$ ). Notably, the average mean values for all measurements (Integration-HH, Integration-HH radius=2, and 
connectivity) are also higher compared to the numbers for Zagreb. While this analysis confirms how those streets are significant within the entire street network, it does not give clear answers to questions on how or why.

Second, we look at comparisons amongst gateway-pathways: (a) historical gateway-pathways versus twentieth century avenue additions, and (b) syntax of historical versus contemporary lines of historical gateway-pathways. At first glance, on the first set of comparisons (a), numeric variations in Table 2 do not suggest a straightforward distinction between historical gateway-pathways (Group 1) and contemporary avenues (Group 4). Still, it can be detected that historical axial lines have slightly lower mean (average) results, except for the Vlaška gateway-pathway for which the historical axial lines are the same as the contemporary route. The only clear regularity can be located in the mean Integration-HH radius-2 for which historical gateway pathways have values lower than '3.0’ while all contemporary versions are above the value of ' 3.0 ' - including the previously mentioned exception of Vlaška gateway-pathway that has the same historical and contemporary profile. From the second comparative analysis (b), all three historical gateway-pathways (Group 1) have lower mean values both for integration and connectivity measures compared to their contemporary profile (Group 2 and 3). This is not surprising since the characterisation method of Group 1 identifies historical routes based on what was preserved in the contemporary axial map. More interesting is the fact that maximum values are the same for historical and contemporary selections, which means that the new areas appearing in contemporary routes have not increased syntactic values for the gateway-pathway. In other words, the historical lines of the gateway-pathways show greater syntactic prominence within the contemporary spatial configuration of the route. This raises inquiries for future research: specifically, to examine syntactic differences for street 
segments across the city for streets with and without historic background of pre-existing routes; and to identify whether spatial syntax measures can detect spatial history layers and spatial heritage of urban landscapes.

The measure of connectivity appears to indicate spatial transformation processes for the historical gateway pathways. Petrinjska and Savska are gateway-pathways that have undergone significant levels of physical transformation and character since their emergence. We notice how these streets show marked differences between the mean connectivity values for the historical and contemporary lines of the gateway-pathway. On the contrary, Vlaška whose spatial configuration maintains the continuity of the historical layout shows no difference. Ilica has suffered two significant breaks by the railway line but overall it maintained a parallel line to the railway on the north and south - in this case the connectivity difference is below 1. Petrinjska and Savska also have the highest maximum values for integration-HH (i.e. calculated for the entire street network) amongst the historical gateway-pathways (Group 1).

The distinct profile of Ilica (Figure 5) and Vlaška (Figure 6) compared to Savska (Figure 7) and Petrinjska (Figure 8) is not only noticeable in terms of spatial syntax, but also in terms of historical functions of the routes in the urban landscape. Unlike Ilica and Vlaška routes which are east-west urban axis, parallel to the Medvednica mountain and on the borderline between the plain and hilly topography, Savska and Petrinjska are pathways going towards the south River Sava. Savska is crossing the River by three bridges with different roles: a railway bridge from 1939; a reused road bridge from 1938 which was turned into pedestrian and positioned where an older bridge from 1783 had been; and a road bridge from 1981 with tram line and three lanes in each direction for vehicles. Petrinjska had for short period the first pontoon bridge in Zagreb in 1764. Savska occupied some specific functions along the way which changed their location 
through history such as: the Zagreb fair (reused space for student centre), a technical museum, the town swimming area, a railway line parallel to the Savska road, a tram line and a tramway storage area, various factories and inns. Petrinjska is dominated with residential and office buildings from different periods with even few houses from the eighteenth century. It is characterised with few specific buildings such as a police station, a kindergarten building in the courtyard of one block, a bank, a public garage, an hotel, the main city post office and the main railway station at the south end where the historical pathway breaks its continuity. Ilica and Vlaška were very vivid and full of crafts and shops throughout their history and are mixed used shopping streets.

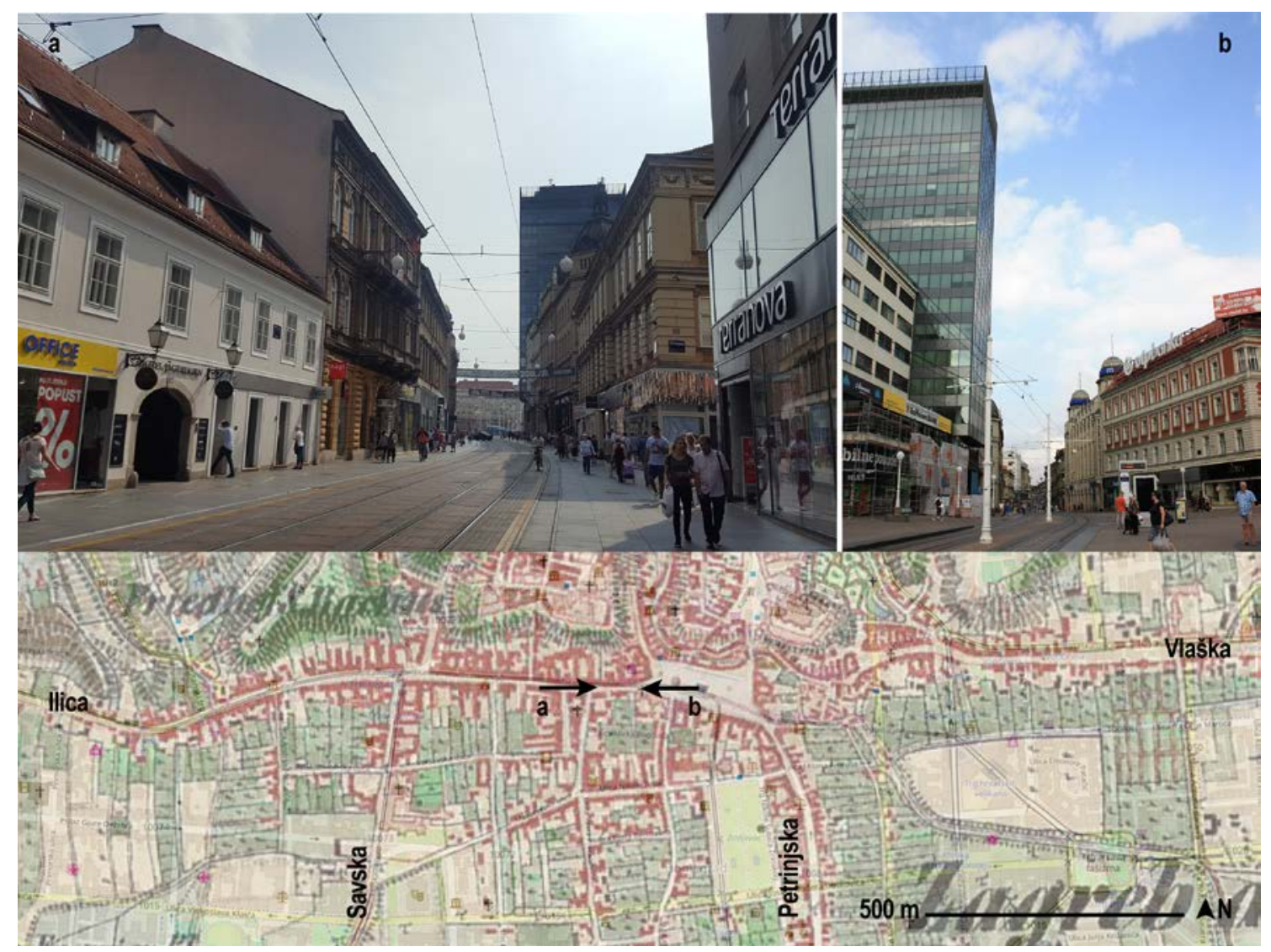

Figure 5. Contemporary photos of Ilica route in Zagreb (ㄷ Ana Sopina 2018) with locations on the historic map of the Second military survey of the Habsburg Empire for Croatia, 1865-1869 (Timár et al. 2006), (C) Österreichisches Staatsarchiv, (C) Arcanum Adatbázis Kft, (c) OpenStreetMap. 

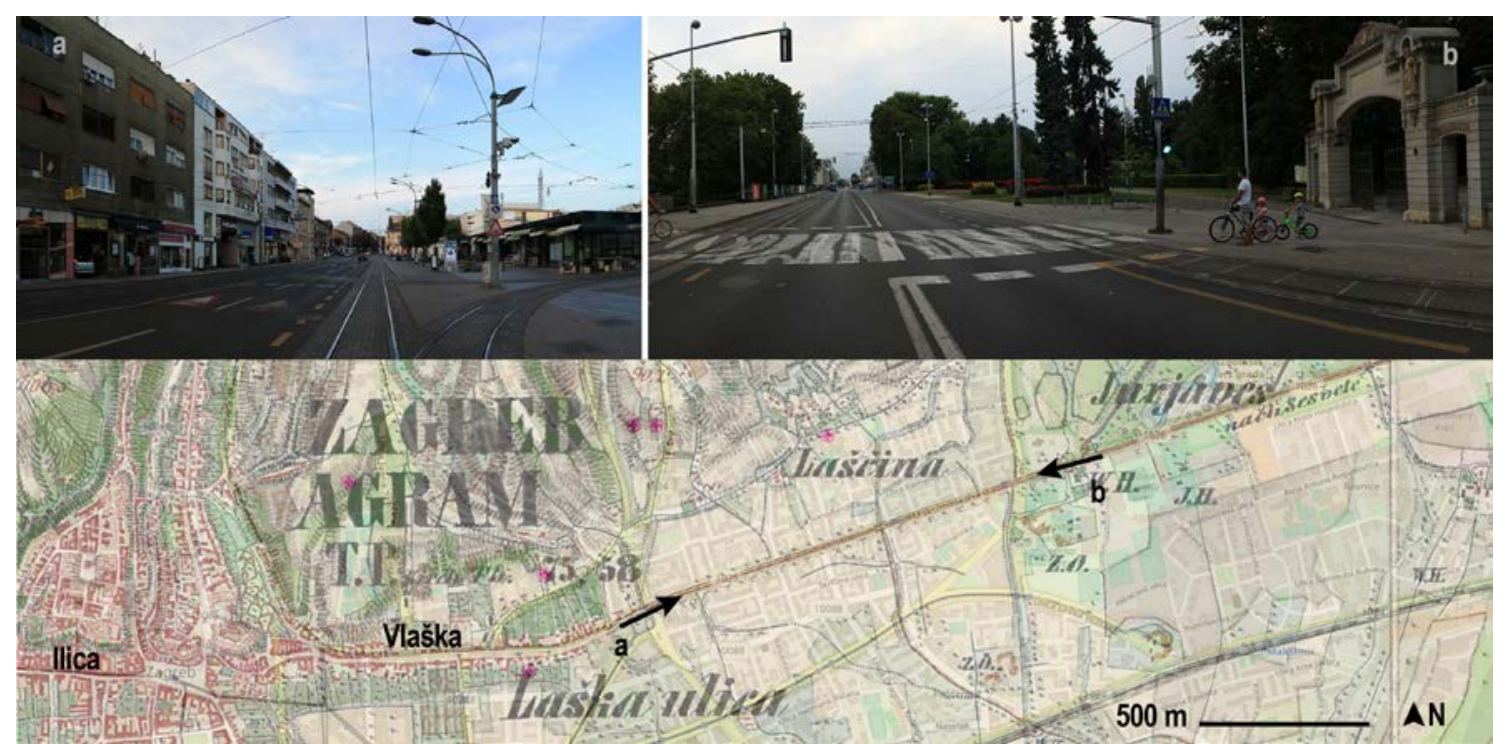

Figure 6. Contemporary photo of Vlaška route in Zagreb (c) Ana Sopina 2018) with locations on the historic map of the Second military survey of the Habsburg Empire for Croatia, 1865-1869 (Timár et al. 2006), (C) Österreichisches Staatsarchiv, ㄷ Arcanum Adatbázis Kft, (c) OpenStreetMap.

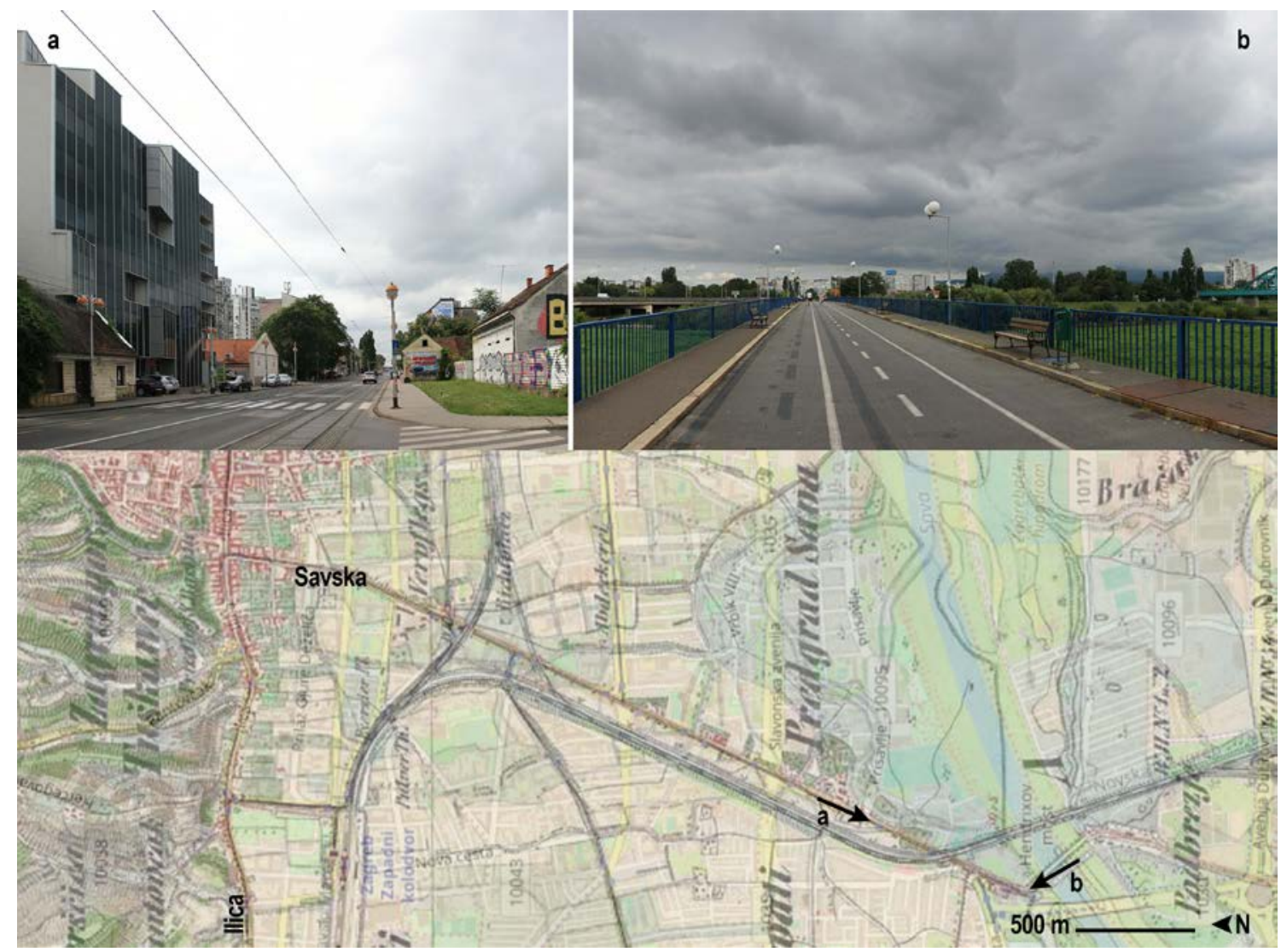

Figure 7. Contemporary photo of Savska route in Zagreb (ㄷ Ana Sopina 2018) with locations on the historic map of the Second military survey of the Habsburg Empire for 
Croatia, 1865-1869 (Timár et al. 2006), (C) Österreichisches Staatsarchiv, (C) Arcanum Adatbázis Kft, (c) OpenStreetMap.

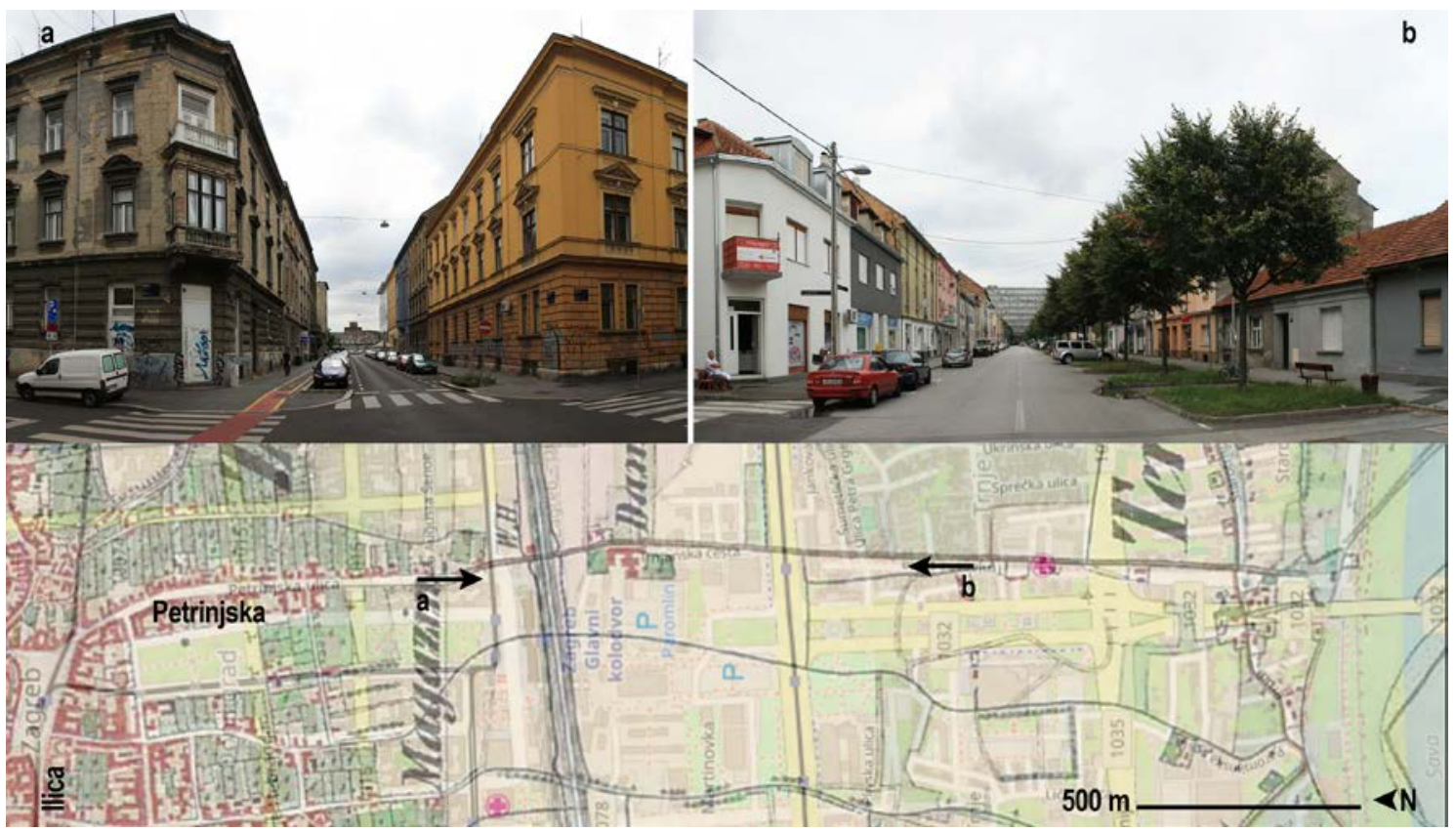

Figure 8. Contemporary photo of Petrinjska route in Zagreb (ㄷ Ana Sopina 2018) with locations on the historic map of the Second military survey of the Habsburg Empire for Croatia, 1865-1869 (Timár et al. 2006), (C) Österreichisches Staatsarchiv, (C) Arcanum Adatbázis Kft, (c) OpenStreetMap.

The study's findings raise the interesting question of whether street network densification processes along gateway-pathways relate to the historical role of the pathway in terms of spatial integration - namely if centrality is a process (Hillier 1999), does higher integration attract greater spatial change or, in Hillier's words, grid deformation? This question is further explored in the next section with transect analysis. However, for these observations to be meaningful, further comparisons with other streets within the spatial configuration are needed, as well as comparisons with gateway-pathway transformations found in other cities. 
Results suggest how it is difficult to identify gateway-pathways within a spatial configuration through their syntactic profile alone. However, syntactic descriptions do align with the typological classification of gateway-pathways. Specifically, there seems to be a relationship between the attributes of connectivity and integration with the degree of spatial transformation along the studied gateway-pathways. The following section proposes the use of transect analysis as means to further examine the relationship between the contemporary syntactic profiles of gateway-pathway and their spatial histories.

\section{Transect analysis of historical gateway-pathways}

In this section we use transect analysis to compare the four historical gatewaypathways. The aim is to address both an analytical and a methodological query, as follows: (1) to consider how typological distinctions of gateway-pathway might relate to integration, and specifically the $10 \%$ integration core, and (2) to test whether we can retrieve information about spatial history without the use of cartographic redrawing methods. Cartographic redrawing (Pinho \& Oliveira, 2009; Dhanani, 2016) is an established method for syntactic-morphological analysis of spatial histories (Griffiths, 2012). This approach is time consuming because it involves working backwards from contemporary maps to create syntactical models of past urban environments, which explains why comparative studies of urban spatial histories using this technique are relatively rare. Furthermore, considering the dimensions of heritage as contemporary commodity, an idea that distinguishes heritage from history according to Ashworth (1994: 16), then spatial heritage needs to be understood as a product of both spatial history and contemporary use and function in the urban landscape. 


\section{The four gateway-pathways}

The case studies of gateway-pathways in Zagreb are all indirect initial typologies, since these routes do not lead to the walled historic cores: Ilica and Vlaška were regional and transit routes, Savska regional, while Petrinjska local. Table 4 summarises basic descriptions of classification criteria of these routes. In Zagreb, there are three types of gateway-pathways according to their location/role in the urban landscape and their transformation degree. Ilica and Vlaška pathways provide east-west connectivity. Their spatial layout maintains a continuous linear character. They converge in the main public square Trg bana Josipa Jelačića, forming almost one continuous axis in Zagreb’s layout. In terms of the urban landscape topography, these gateway-pathways together form a border between the slopes of Medvenica hill and the River Sava plane; starting from the main square, Ilica is leading to the west, and Vlaška to the east. Both Ilica and Vlaška routes remained gateways and they now connect layers of cultural and natural landscapes, from historical centre to the periphery formed by various architectural styles and public places in the overall urban fabric of the city.

The Savska pathway is an avenue that was partially redirected in 1981 due to the construction of a new bridge. While historically the gateway-pathway was mostly used as a local route, the $20^{\text {th }}$ century transformation turned it into a new city entrance to serve vehicular traffic. The Savska route remained an urban gateway becoming the highway connection on and southwest after the Sava bridges where historical south part of the gateway-pathway was redirected onto its contemporary highway route. Historical south part became secondary, local connection to that peripheral areas of Zagreb and kept more curved/natural layout character.

Petrinjska stopped being a gateway rather sooner (this is obvious from the differences between the eighteenth and nineteenth century or the first and second 
military surveys). An additional break of route continuity makes Petrinjska a 'disappeared gateway-pathway’ or a pathway with discontinuity which is a rare type of gateway-pathway classification out of the wider study of Central European cities. The comparative georeferenced data between the historical maps and contemporary axial map shows only small fragments of the original historical route from the $18^{\text {th }}$ century left in the contemporary configuration.

Referring again to the question on spatial integration and degree of change, it is understood that Petrinjska and Savska - the pathways with the maximum integration values in the contemporary axial model among historical pathways of Zagreb - show the greatest degree of transformation. Transect analysis further examines this argument to shed light specifically on whether the topographic relation of the gateway pathway to the integration core impacts spatial history. The hypothesis is that gateway-pathways with a spatial history of lower degrees of transformation have maintained their spatial identity over time, hence they are part of the spatial heritage of the urban landscape.

\section{Methodology}

To perform historical, transect analysis in Zagreb, we used ArcGIS software to superimpose the axial model of Zagreb over historical maps either scanned (Skalamera 1994) or retrieved from the mapire.eu archive (Biszak, et al. 2012). The degree of change in the network is measured by the breaks in continuity. For the comparison of the four gateway-pathways we use descriptive data taken from transect analysis. Twostep transects are mapped for the four historical gateway-pathways (Ilica, Vlaška, Savska, and Petrinjska), to represent the historical route and its immediate surroundings on the contemporary map (c.2012). We take as a transect's starting point the historical axial lines that are preserved in the contemporary axial map (this includes lines which have changed length but are traces of historical lines). The depth of historical axial lines 
is zero (depth=0), and they form the basis of the pathway transect. From this basis, we map the transect for each pathway by adding axial lines which are one (depth=1) and two (depth=2) steps/turns away. By selecting traces of historical (original) route from the contemporary axial model, the transect comparison involves information about the historical layout structure as well as the spatial transformation that emerged during urban growth.

Figure 11 illustrates this process on the contemporary axial map (c.2012) by showing the traces of the historical gateway-pathway in black colour (axial lines with depth=0), while the immediate surrounding streets are marked in grey (axial lines which are one-step and two-steps away from the selected traces of gateway-pathway).

\section{Analysis}

Overlap analysis reveals important characteristics of historical 'transit gatewaypathways' in Zagreb. In space syntax research, 'path overlap' analysis is earlier used by Vaughan et al. (2013) to compare the syntactic role of a path within a street network when analysing the spatial configuration at different catchment radii in Depthmap software. Here, we use overlap analysis of the transects and the superimposed $10 \%$ integration core (Figures 9 and 10). When combining the four transects, the integration core is picked up at an overlap of 472 lines out of 1324 (Figures 9 and 10). This means that $36 \%$ of the axial lines comprising the $10 \%$ integration core of the Zagreb contemporary street network are lines that belong to historical gateway-pathways (black lines in Figures 9 and 10) and immediately adjacent streets (up to two steps away from the gateway-pathway; grey lines in Figure 11). This could indicate that the city's growth happened along these lines and that they are distinctive in the overall urban network, which is a basis for forming a syntactic gateway-pathway definition. 

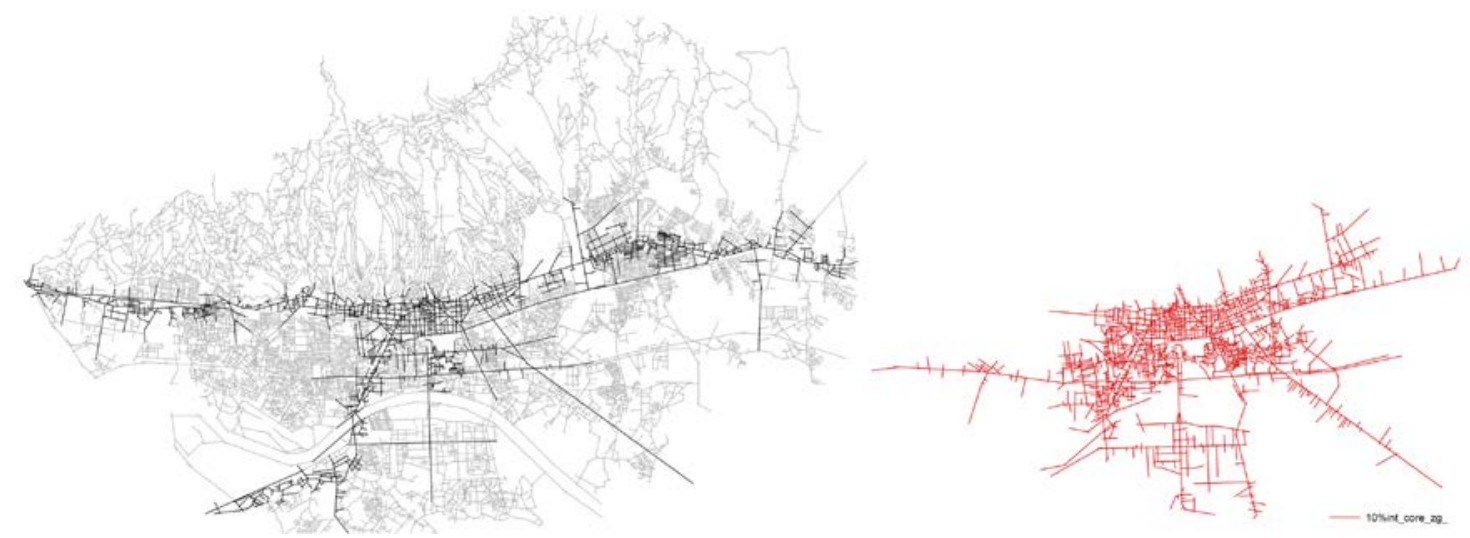

Figure 9. Merged four two step transects of case study pathways (black, left) and 10\% integration core (red, right). (c) Tamara Zaninović

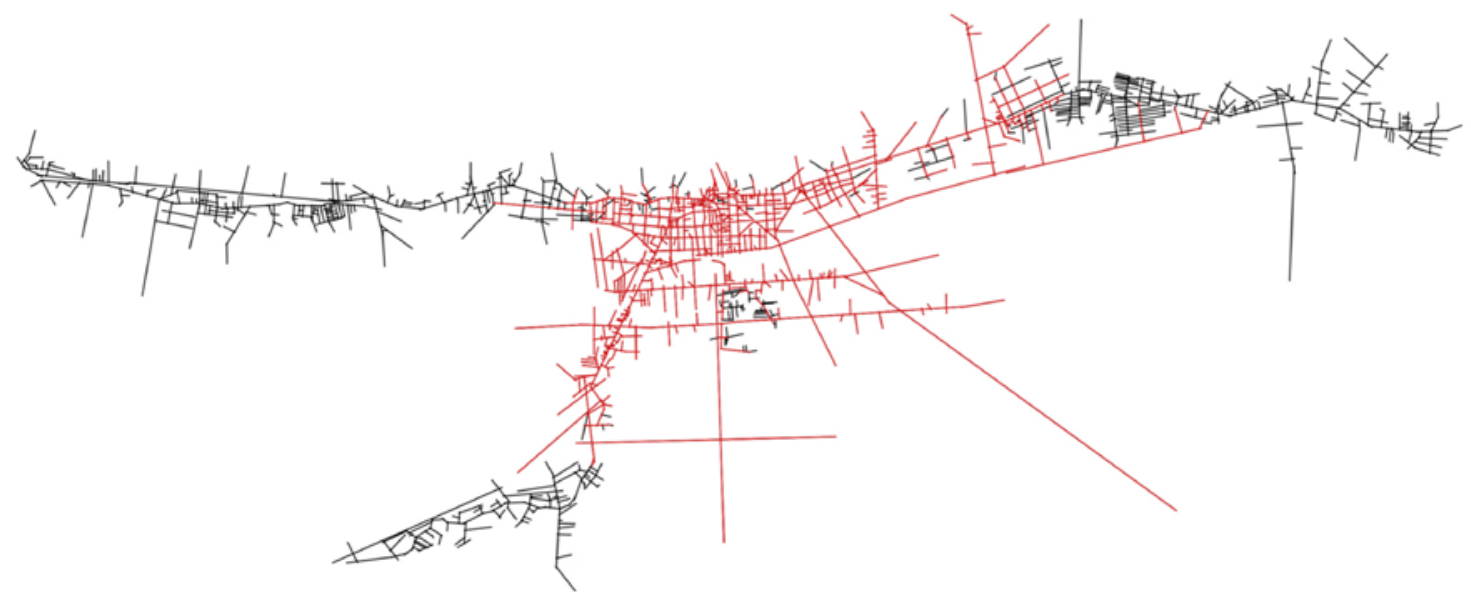

Figure 10. Overlap marked in red of merged transects with $10 \%$ integration core. (C) Tamara Zaninović 


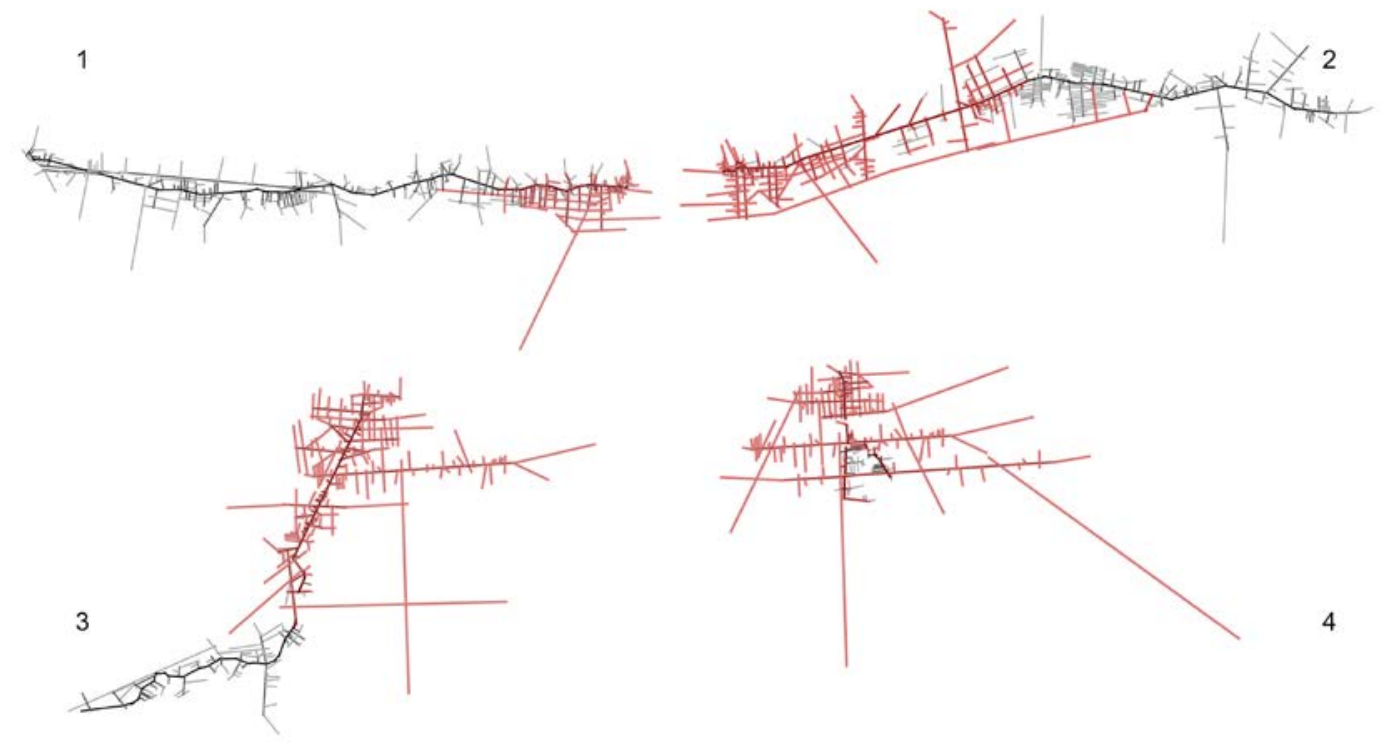

Figure 11. Transects of case study pathways with 10\% core overlap -1) Ilica, 2)

Vlaska, 3) Savska and 4) Petrinjska. Key: black = the historic pathway trace; grey = the transect lines one or two-steps away from the historic pathway trace; red = axial lines of transects that are also part of the $10 \%$ integration core. (C) Tamara Zaninović

The next step is to look at transects individually (Figure 11). Overlap analysis identifies differences in the percentages of pattern overlaps (red line shows 2-step transect lines which belong to the $10 \%$ integration core). Visual comparison of the four transect 2-step patterns and their overlaps with $10 \%$ integration core indicates that Petrinjska pathway (no. 4 in Figure 11) is quite different from the other gatewaypathways and that Ilica (no. 1 in Figure 11) appears to be on the other end of the spectrum, having the fewest amount of high integration red lines. Quantitative comparisons and descriptive statistics give a better understanding of the differences in the transect profile of the four gateway-pathways. Table 3 presents the four analysed pathways in four columns with four groups of information (table rows): 
(1) Number of axial lines, given for: 'Step 0' (depth=0), i.e. selected lines in Depthmap program for step depth calculation which are the historical-gateway pathway lines; 'Step 1' (depth=1), i.e. one-step away axial lines from the initially selected lines; 'Step 2', i.e. two-step away axial lines from the initially selected ones; the sum of 'Step 1' and 'Step 2' lines for each historical gatewaypathway.

(2) Overlap percentages: the first overlap percentage shows how much of the pathway transect is a part of the $10 \%$ integration core calculated by dividing number of overlapped lines with total number of transect lines. The second overlap is how much of the integration core is occupied by the gatewaypathway. This is calculated by dividing number of overlapped lines form each transect with total number of lines in integration core which is $n=1324$. The third percentage overlap gives the relation between the transects and the city of Zagreb as information of how much of the overall city is occupied by transect which is calculated by dividing total number of transect lines with total size of Zagreb axial map which is 13,236.

(3) Values for axial integration: Integration-HH for radius radius=n (calculated for the entire spatial configuration) and radius $=2$ (calculated for two axial steps away).

(4) Transect density: this is a measure introduced by the authors and is calculated by dividing the total length of the axial lines of the historical gateway-pathway ('Step 0') by the sum of 'Step 1' and 'Step 2' axial lines appearing in the pathway transect. In this group, we also list connectivity values for the transects since this shows the number of line connections, and therefore, it can be considered as another proxy for transect density. 


\begin{tabular}{|c|c|c|c|c|}
\hline Historical Pathways transect system & Ilica & Vlaška & Savska & Petrinjska \\
\hline \multicolumn{5}{|c|}{ Number of lines } \\
\hline N Total & 355 & 390 & 305 & 186 \\
\hline $\mathrm{N}$ step 0 & 29 & 16 & 25 & 9 \\
\hline $\mathrm{N}$ step 1 & 116 & 106 & 85 & 45 \\
\hline $\mathrm{N}$ step 2 & 210 & 268 & 195 & 132 \\
\hline $\mathrm{N}$ step 1 and 2 & 326 & 374 & 280 & 177 \\
\hline $\begin{array}{l}\text { N of total overlapped lines in transect system (step } 0 \text {, } \\
1 \text { and } 2 \text { ) with } 10 \% \text { integration core }\end{array}$ & 88 & 162 & 205 & 138 \\
\hline $\begin{array}{l}\mathrm{N} \text { overlapped lines in pattern network of gateway- } \\
\text { pathway (step } 1 \text { and } 2 \text { ) with } 10 \% \text { integration core }\end{array}$ & 80 & 154 & 200 & 130 \\
\hline \multicolumn{5}{|c|}{ Total line length (sum values, $\mathrm{m}$ ) } \\
\hline LL step 0 lines & 12598 & 12995 & 9646 & 2997 \\
\hline LL step 0 overlapped lines with $10 \%$ int. core & 2840 & 6614 & 4052 & 2830 \\
\hline LL steps 1 and 2 & 84739 & 120921 & 95070 & 70806 \\
\hline TLL steps 0,1 and 2 & 97337 & 133916 & 104716 & 72880 \\
\hline \multicolumn{5}{|c|}{ Overlap percentage (\%) } \\
\hline $\begin{array}{l}\text { \% of total line length of the historical pathway lines } \\
(\text { step=0) which is part of the integration core that } \\
\text { overlaps with } 10 \% \text { integration core } \\
\text { N LL step } 0 \text { overlapped / N LL step } 0\end{array}$ & $22.5 \%$ & $50.9 \%$ & $42 \%$ & $94.4 \%$ \\
\hline $\begin{array}{c}\text { \% of historical pathway transect systems (N Total } \\
\text { includes steps 0,1 and 2) that overlaps with } 10 \% \\
\text { integration core } \\
\text { N total overlapped / N Total }\end{array}$ & $24.8 \%$ & $41.5 \%$ & $67.2 \%$ & $74.2 \%$ \\
\hline $\begin{array}{c}\text { \% of transects steps } 1 \& 2 \text { that overlaps with } 10 \% \\
\text { integration core } \\
\text { N overlapped / N step } 1 \text { and } 2\end{array}$ & $24.5 \%$ & $41.2 \%$ & $71.4 \%$ & $73.4 \%$ \\
\hline $\begin{array}{l}\text { \% of overlapped lines in the } 10 \% \text { integration core } \\
\text { N overlapped / } 1324 \text { lines }\end{array}$ & $6.70 \%$ & $12.2 \%$ & $15.5 \%$ & $10.4 \%$ \\
\hline $\begin{array}{l}\text { \% of overlapped lines in overall city network } \\
\mathrm{N} \text { total / } 13236 \text { lines }\end{array}$ & $2.7 \%$ & $3.0 \%$ & $2.3 \%$ & $1.4 \%$ \\
\hline \multicolumn{5}{|c|}{ Integration $\mathrm{HH}$} \\
\hline Rn MAX & 0.778 & 0.770 & 0.784 & 0.784 \\
\hline Rn MEAN & 0.565 & 0.613 & 0.652 & 0.686 \\
\hline R2 MAX & 6.743 & 7.316 & 6.743 & 6.743 \\
\hline R2 MEAN & 2.225 & 2.548 & 2.654 & 2.800 \\
\hline \multicolumn{5}{|c|}{ Transect density } \\
\hline LL step 0 / N step 1 and 2 & 38.6 & 34.8 & 34.5 & 11.7 \\
\hline $\begin{array}{c}\text { Connectivity MAX } \\
\text { steps } 0,1,2\end{array}$ & 47 & 26 & 47 & 47 \\
\hline $\begin{array}{c}\text { Connectivity MEAN } \\
\text { steps } 0,1,2\end{array}$ & 3.910 & 4.474 & 4.295 & 5.016 \\
\hline
\end{tabular}

Table 3: Axial syntactical profile of the historical gateway pathways two-step depth transects. (C) Tamara Zaninović

To interpret results from transect analysis in relation to spatial transformations of the four gateway-pathways, we need to consider the number and type of breaks observed in the continuity of the historical route (Table 4). Breaks are important for analysing the spatial change over time because they are the evidence of 'historical incidents' in physical processes of urban landscape formation. 


\begin{tabular}{|c|c|c|c|c|}
\hline $\begin{array}{l}\text { Historical Pathways } \\
\text { transect system }\end{array}$ & Ilica & Vlaška & Savska & Petrinjska \\
\hline $\begin{array}{l}\text { Description of } \\
\text { geographical directions } \\
\text { for linear gateway- } \\
\text { pathway in the zero- } \\
\text { step-depth selection }\end{array}$ & $\begin{array}{l}\text { East-west } \\
\text { connection } \\
\text { (from the main } \\
\text { square to east) }\end{array}$ & $\begin{array}{c}\text { East-west } \\
\text { connection } \\
\text { (from the main } \\
\text { square to west) }\end{array}$ & $\begin{array}{l}\text { North-south } \\
\text { diagonal } \\
\text { connection (east } \\
\text { from central } \\
\text { urban axis) } \\
\end{array}$ & $\begin{array}{l}\text { North-south diagonal } \\
\text { connection (first street } \\
\text { to the west of central } \\
\text { axis) }\end{array}$ \\
\hline $\begin{array}{c}\text { Initial historical } \\
\text { typology of gateway- } \\
\text { pathway (regional/local; } \\
\text { direct/indirect/transit) }\end{array}$ & $\begin{array}{c}\text { Regional } \\
\text { indirect transit }\end{array}$ & $\begin{array}{c}\text { Regional } \\
\text { indirect transit }\end{array}$ & Regional indirect & Local indirect \\
\hline $\begin{array}{l}\text { Layout route character } \\
\text { (natural or avenue) }\end{array}$ & $\begin{array}{l}\text { Natural with } \\
\text { historical partial } \\
\text { avenue } \\
\text { redirecting }\end{array}$ & $\begin{array}{l}\text { Dominated } \\
\text { avenue } \\
\text { character }\end{array}$ & $\begin{array}{l}\text { First part between } \\
\text { the urban core } \\
\text { and the River } \\
\text { Sava is avenue } \\
\text { character after the } \\
\text { River in the } \\
\text { second part it is } \\
\text { natural character }\end{array}$ & Natural \\
\hline $\begin{array}{l}\text { Route transformation } \\
\text { models during historical } \\
\text { development (no } \\
\text { transformation = route } \\
\text { continuity/partial } \\
\text { discontinuity of } \\
\text { route/route } \\
\text { redirecting/discontinuity } \\
\text { = disappeared gateway } \\
\text { model) } \\
\end{array}$ & $\begin{array}{c}\text { Partial } \\
\text { discontinuity } \\
\text { model }\end{array}$ & $\begin{array}{c}\text { Route } \\
\text { continuity } \\
\text { model }\end{array}$ & $\begin{array}{c}\text { Redirecting } \\
\text { model }\end{array}$ & $\begin{array}{l}\text { Route discontinuity } \\
\text { after redirecting } \\
\text { resulted in disappeared } \\
\text { gateway model }\end{array}$ \\
\hline $\begin{array}{l}\text { Number of breaks in } \\
\text { historical zero-step- } \\
\text { depth lines and } \\
\text { continuity: }\end{array}$ & 2 & 0 & 2 & 4 \\
\hline Reasons for the breaks: & Railway & 1 & $\begin{array}{l}\text { Bridge; elevated } \\
\text { roundabout }\end{array}$ & $\begin{array}{l}\text { Railway and historical } \\
\text { transformation of the } \\
\text { route; railway main } \\
\text { station placement with } \\
\text { industrial area; and } \\
\text { east-west dominant } \\
\text { streets connections } \\
\text { from regulation in } \\
1953\end{array}$ \\
\hline
\end{tabular}

Table 4: Qualitative analysis of historical gateway-pathways in the context of spatial history with typological classification. (c) Tamara Zaninović

Petrinjska is the gateway-pathway with the highest number of breaks in the continuity of its historical route. Recalling that it is classified as 'disappeared gatewaypathway’ type because it has undergone a high degree of transformation, it is expected that very few historical axial lines are remaining in the contemporary model of the Zagreb street network. Subsequently, it is expected that it has the lowest number of axial lines in its two-step transect. Visual observations mentioned earlier for the distinct character of the Petrinjska transect, are confirmed by figures in Table 3. Transect 
density Petrinjska is by far the highest amongst the sample. Note here that the value for transect density suggests that a new axial line has emerged for every $\chi$ line length units (where $\chi=$ the transect density value) of the total length of the historical gatewaypathway axial lines. The smaller the value for $\chi$, the higher the number of transect lines that are generated for the historical gateway-pathway length. Petrinjska historical gateway-pathway has generated a new transect line every 11.4 axial length units (Savska every 34.5 axial length units; Vlaška every 34.8 units; and Ilica every 38.6 units). At the same time $74.2 \%$ of the transect lines fall within the integration core. This means that overall the transect is highly integrated; in fact, syntactic analysis confirms that Petrinjska transect has the highest mean integration value amongst the four $(\mathrm{Rn}$ Mean Integration $\mathrm{HH}=0.69$ ), calculated for a radius catchment of the entire Zagreb street network. This suggests that the higher the overall integration of the gatewaypathway in the contemporary urban landscape (which is in turn implied by high overlap with the $10 \%$ integration core), then the higher the chances for this pathway of having undergone substantial grid densification in its surroundings. For this proposition to be systematically tested, we would need a larger sample of gateway-pathways including comparisons of gateway-pathways from different cities.

In general, the trend appears to follow across the sample of four streets (see Figure 12), which suggests it would be worthwhile to further investigate the validity of this argument in future studies. The trend is more evident for the extreme cases of Petrinjska and Ilica in terms of overlap, whereas for the pathways in the middle, Savska and Vlaška, the difference in terms of transect density becomes fuzzier.

As described in the beginning of this section, Vlaška and Ilica transects belong to the same 'transit gateway-pathway' type because of how they are located in the landscape topography, as well as because of their transformation processes. These 
allowed them to sustain shopping-based uses and continue existing as gateways, nowadays more local but with regional significance because of their connections to the highway system. Together they form a nearly continuous east-west connection that passes through the main city square, which is the reason for considering them as transit typology. They both have sections where mixed-use shopping is the prominent land use type in central part of the city. In spite of historical breaks in the spatial layout of Ilica, the historical trail of the gateway-pathway is maintained in the contemporary spatial layout of Zagreb, which is a contradiction. Examining the syntactic profile of the gateway-pathways we find a potential explanation for this.

$\longrightarrow$ percentage overlap (steps $0,1,2) \longrightarrow$ transect density

74.2

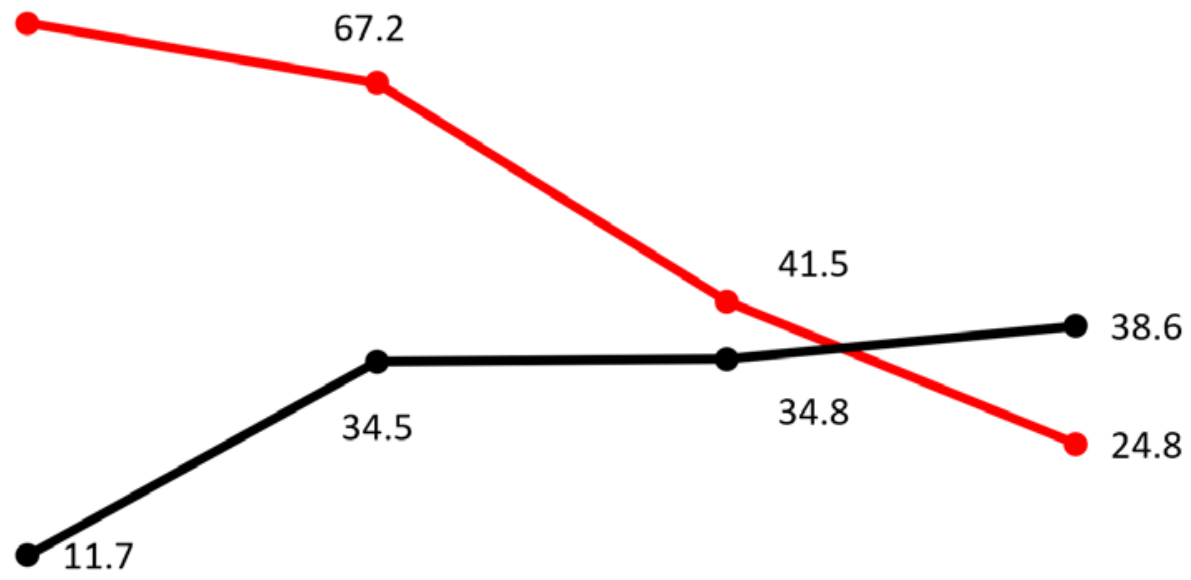

$\mathrm{P}$

S

V

।

Figure 12. Graph showing relationship between transect density (black) and the gateway-pathway 2-step transect overlapping with the $10 \%$ highest integration values (red percentage overlap). (C) Tamara Zaninović 
Table 5 shows the mean connectivity and mean integration values for the four historical gateway-pathways ('Step 0' lines) compared to the values for the remaining lines of the two-step transects (i.e. the 'Step 1' and 'Step 2' lines). Looking at the difference (absolute and relative) in values between the historical gateway-pathway and its immediate surroundings, we notice a marked difference for Vlaška and Ilica pathways compared to Savska and Petrinjska: Vlaška and Ilica stand out from their immediate surroundings in terms of syntactic profile, whereas the areas around Savska and Petrinjska show similar syntactic character with the gateway-pathway. If the hypothesis that higher integration means a greater degree of transformation is valid, then the surroundings of Vlaška and Ilica being much less connected than these two main routes (see in Table 5, the relative difference percentages for mean connectivity), might have acted as a protection layer from potential emergence of high spatial transformation in the transect areas of these gateway-pathways.

\begin{tabular}{|c|c|c|c|c|}
\hline $\begin{array}{c}\text { Historical } \\
\text { Pathways transect } \\
\text { system }\end{array}$ & Ilica & Vlaška & Savska & Petrinjska \\
\hline \multicolumn{5}{|c|}{ Transect density: } \\
\hline $\begin{array}{c}\text { LL step } 0 / \mathrm{N} \text { step } \\
1 \text { and } 2 \\
\end{array}$ & 38.6 & 34.8 & 34.5 & 11.7 \\
\hline \multicolumn{5}{|c|}{ Integration HH: } \\
\hline MEAN step 0 & 0.560 & 0.638 & 0.560 & 0.687 \\
\hline MEAN steps 1,2 & 0.566 & 0.612 & 0.660 & 0.686 \\
\hline $\begin{array}{c}\text { Absolute } \\
\text { difference } \\
\text { step } 0 \text { - steps } 1,2\end{array}$ & -0.006 & 0.026 & -0.100 & 0.001 \\
\hline $\begin{array}{c}\text { Relative (\%) } \\
\text { difference } \\
\text { step 0 - steps 1,2 }\end{array}$ & $-1.1 \%$ & $4.1 \%$ & - $17.9 \%$ & $0.1 \%$ \\
\hline \multicolumn{5}{|c|}{ Connectivity } \\
\hline MEAN step 0 & 6 & 8.563 & 5.560 & 5.857 \\
\hline MEAN steps 1,2 & 3.724 & 4.299 & 4.211 & 4.977 \\
\hline $\begin{array}{c}\text { Absolute } \\
\text { difference step } 0 \text { - } \\
\text { steps } 1,2 \\
\end{array}$ & 2.276 & 4.264 & 1.049 & 0.880 \\
\hline $\begin{array}{c}\text { Relative (\%) } \\
\text { difference step } 0 \text { - } \\
\text { steps } 1,2\end{array}$ & $37.9 \%$ & $49.8 \%$ & 18.9 \% & $15.0 \%$ \\
\hline
\end{tabular}

Table 5: Axial profile of the four historical gateway-pathways ('Step 0’ lines) compared to the values for the remaining lines of the two-step transects ('Step 1' and 'Step 2' lines). (C) Tamara Zaninović and Garyfalia Palaiologou 
For Vlaška and Ilica, the distinct syntactic role of the historical gatewaypathway within its immediate spatial configuration (Table 5) suggests how spatial prominence is maintained within the surrounding contemporary urban landscape. In addition, lower degrees of axial lines density for the transect (Table 3, Figure 12) imply lower rates of grid densification processes during urban growth. Namely, these gateway-pathways are spatially distinctive within their urban setting as well as maintaining a certain degree of spatial continuity/change over time. Spatial prominence and degree of spatial continuity/change over time could then be identified as key characteristics of spatial heritage.

Future research could test this argument by assessing the spatial culture of gateway-pathways in relation to their historical cultural and socio-economic profile to confirm whether or not spatial prominence and lower densification suggests also diachronic continuity in cultural affordance. For example, the role of spatial prominence is evident for London high streets, which can arguably be considered part of London's urban heritage (Griffiths, 2015; Palaiologou, 2015) as 'the most common public asset' (We Made That and LSE Cities 2017). Furthermore, the thresholds for spatial prominence and spatial continuity/change (i.e. grid densification), according to which a gateway-pathway would be considered spatial heritage, need definition. (A pertinent question is whether these thresholds need to be absolute or relative numbers according to the transect and/or the entire spatial configuration.)

\section{Transect analysis results}

This study examined the spatial profile of historical transit gateway-pathways in Zagreb to identify whether the use of space syntax analysis can provide a mathematical description for spatial heritage. Syntactic analysis of the contemporary axial model for Zagreb (c.2012) did not provide a straightforward typological distinction for historical 
gateway-pathways. When comparing the syntactic profile of historical gatewaypathways, however, we identify how the measure of connectivity is useful. It highlights marked differences between the mean connectivity values for the historical and contemporary lines of the gateway-pathway; the greater the difference, the greater the degree of spatial transformation. Therefore, the space syntax approach shows a possible way to test gateway-pathway typologies quantitatively.

Transect analysis for historical gateway-pathways was tested as an alternative to cartographic redrawing methods. By overlapping two-step transects of the four historical gateway-pathways with the lines comprising the $10 \%$ integration core, we were able to identify a relationship between the contemporary syntactic profiles of the pathways and their spatial history. Transect analysis suggests two criteria for spatial heritage: a) spatial prominence of the historical gateway-pathway within its surrounding streets; and b) spatial continuity via lower degrees of grid densification. Overlap analysis, indicates that the higher the overlap of the transect with the $10 \%$ integration core, the higher the density of street lines is observed in the contemporary surroundings of the gateway-pathway. Street density can be seen as a proxy to urbanisation process in the urban landscape, therefore it is worth exploring further whether higher integration for gateway-pathways correlates with higher degrees of surrounding street density and urban transformation.

The approach of transect analysis method in this paper identified historic gateway-pathways Vlaška and Ilica as heritage of gateway-pathways. They are historical routes which still connect the historic urban core with nowadays periphery. This approach to tangible heritage identification is not assigned by visual, aesthetic or symbolic assessment of the built environment. Instead, it follows an alternative analytical process of assessing configurational spatial characteristics of the urban 
landscape. Overlap analysis, further, identified Petrinjska, which is the most transformed pathway in Zagreb, as an outlier in terms of syntactic profile. These results provide mathematical evidence for the distinct role of specific historical gatewaypathways in the urban landscape. Furthermore, they have the potential to define a mathematical matrix for the spatial heritage of cities, a new heritage type which could be considered in the mapping and evaluating steps of the historic urban landscape approach.

\section{Conclusions}

This paper proposes the value of spatial history in applications of landscape approaches to urban conservation. It develops the theoretical and methodological grounds for syntactic (i.e. quantitative) descriptions of the urban landscape in terms of spatial heritage. The study of the spatial history to identify spatial heritages falls within a wider effort to acknowledge the role of culture and heritage in the sustainability agenda.

The work introduces Zagreb into the space syntax portfolio and historical gateway-pathways as urban street typology. The study suggests how criteria for the heritage of gateway-pathways include their spatial prominence and spatial continuity, and shows how these pathways maintain over time a distinct role in the urban landscape. They are preserved in the urban landscape as distinct routes supported by their spatial configuration, which is indicated by low levels of spatial change and grid deformation. In other words, heritage gateway-pathways show a sustainable spatial profile. This proposition makes the case for the necessity of further research into the relationship between spatial and cultural sustainability. It also proposes that to truly incorporate and apply a landscape-based approach, the 2011 Recommendation for the Historic Urban Landscape by UNESCO needs to look beyond established definitions of tangible heritages, consider new analyses for assessing the urban landscape beyond an 
aesthetic and visual appreciation, and consider heritage formation as a diachronic process.

Research undertaken for this paper has identified a constructive link between urban heritage studies and space syntax theory. Space syntax enables an active understanding of spatial heritage in terms of historical spatial-morphological processes, while transect analysis introduced in the paper (i.e. the transect density measure) opens new methodological prospects for historical studies of street networks. Further comparative research on spatial histories of urban landscapes could clarify spatial metrics for spatial heritage and aim to better articulate the role of urban streets as alternative heritages and drivers for cultural sustainability.

\section{Acknowledgements}

Syntactic research was conducted by Tamara Zaninović as guest researcher at The Bartlett School of Architecture in UCL, in 2016. The research was partially supported by the Croatian Science Foundation under the project 'Heritage Urbanism - Spatial and Urban Models for Revival and Enhancement of Cultural Heritage' (HERU HRZZ 2032; head of the project Prof.dr.sc. Mladen Obad Šćitaroci; 2014-2018) and University of Zagreb founding under the research called ‘Urbanscape Emanation' (head of the project Prof.dr.sc. Bojana Bojanić Obad Šćitaroci, 2014-2016). 


\section{References:}

Ashworth, G.J. 1994. From history to heritage - from heritage to identity: in search of concepts and models. In: G. J. Ashworth \& P. J. Larkham, P. J., eds., Building a new heritage: tourism, culture and identity in the New Europe. London: Routledge, pp. 13-30.

Bandarin, F. \& van Oers, R. 2012. The Historic Urban Landscape: managing heritage in an urban century. West Sussex: John Wiley \& Sons.

Bandarin, F. \& van Oers, R. eds. 2014. Reconnecting the city: the Historic Urban Landscape Approach and the future of urban heritage. West Sussex: John Wiley \& Sons.

Biszak, E., Kulovits, H., Biszak, S., Timar, G., Molnar, G., Szekely, B., Janke, A. \& Kenyeres, I. 2014. Cartographic heritage of the Habsburg Empire on the web: the MAPIRE initiative. In: 9th International Workshop on Digital Approaches to Cartographic Heritage, 9: 26-31. [online] [Accessed 20 June 2017]. Available at: <mapire.eu/static/2017-04-21/pub/mapire_biszak_et_al.pdf>

Dhanani, A. 2016. Suburban built form and street network development in London, 1880-2013: An application of quantitative historical methods. In: Historical Methods: A Journal of Quantitative and Interdisciplinary History, 49(4): 230243. [online] [Accessed 1 July 2018]. Available at: $<$ http://dx.doi.org/10.1080/01615440.2016.1220268>

Dino, B., Griffiths, S., \& Karimi, K. 2015. Informality of sprawl? Morphogenetic evolution in post-socialist Tirana. In: City as Organism. New Visions for Urban Life-ISUF Rome 2015-Conference Proceedings, 1: 643-655.

Dino, B., Griffiths, S., \& Karimi, K. 2016. Autocratic planning systems challenged by unregulated urbanisation: Urban transformation in post-socialist Tirana, Albania. In: The Regenerative City. San Francisco: PUARL 2016 Conference.

Dino, B., Griffiths, S., \& Karimi, K. 2017. The post-socialist urban transformation of Tirana in historical perspective: Mapping the ideological dimension of urban growth. In: T. Heitor, M. Serra, J.P. Silva, M. Bacharel, L.C. da Silva eds. 11th International Space Syntax Symposium. [online] Lisbon: Instituto Superior Técnico, Departamento de Engenharia Civil, Arquitetura e Georrecursos, pp. 57.1-57.13 [Accessed 1 July 2018]. Available at: $<$ http://discovery.ucl.ac.uk/10028442/1/Karimi_57.pdf> 
Fredheim, H.L. \& Khalaf, M. 2016. The significance of values: heritage value typologies re-examined. In: International Journal of Heritage Studies, 22(6): 466-481. [Accessed 1 July 2018]. Available at: $<$ DOI:10.1080/13527258.2016.1171247>

Gehl, J. 2010. Cities for People. Washington, Covelo and London: Island Press. Griffiths, S. 2009. Persistence and change in the spatio-temporal description of Sheffield parish 1770-1910. In: D. Koch, L. Marcus \& J. Steen eds. Proceedings of the 7th International Space Syntax Symposium. Stockholm: TRITA-ARKForskningspublikation, pp. 37:1-15.

Griffiths, S. 2012. The use of space syntax in historical research: current practice and future possibilities. In: M. Greene, J. Reyes \& A. Castro eds. In: Proceedings of the 8th International Space Syntax Symposium. PUC, Santiago, Chile, pp. 8193:1-26.

Griffiths, S. 2015. The high street as morphological event. In: Vaughan L (ed), Suburban urbanities: suburbs and the life of the high street. London: UCL Press, pp. 32-50. [Accessed 1 July 2018]. Available at: $<$ https://doi.org/10.14324/111.9781910634134>

Griffiths, S. 2016. Spatial culture, processional culture and the materialities of social memory in nineteenth-century Sheffield. Distinktion: Journal of Social Theory 17(3): 254-75. [Accessed 1 July 2018]. Available at: <https://doi.org/10.1080/1600910X.2016.1183219>

Griffiths, S. \& Lünen, A. von eds. 2016. Spatial cultures: towards a new social morphology of cities past and present. London: Routledge.

Guzmán, P.C., Pereira Roders, A.R., Colenbrander, B.J.F. 2017. Measuring links between cultural heritage management and sustainable urban development: an overview of global monitoring tools. Cities, 60: 192-201. [Accessed 1 July 2018]. Available at: <https://doi.org/10.1016/j.cities.2016.09.005>

Harvey, D. 1973. Social justice and the city. Edward Arnold, London

Harvey, D.C. 2001. Heritage pasts and heritage presents: temporality, meaning and the scope of heritage studies. In: International Journal of Heritage Studies 7(4): 319-38. [Accessed 1 July 2018]. Available at: $<$ https://doi.org/10.1080/13581650120105534> 
Harvey, D.C. \& Waterton, E. 2015. Editorial: Landscapes of Heritage and Heritage Landscapes. Landscape Research 40(8): 905-10. [Accessed 1 July 2018]. Available at: <https://doi.org/10.1080/01426397.2015.1086563>

Hillier, B. 1989. The architecture of the urban object. Ekistics, 56(334/33): 5-21

Hillier, B. 1996. Space is the machine: a configurational theory of architecture. Cambridge: University Press.

Hillier, B. 1999. Centrality as a process: accounting for attraction inequalities in deformed grids. Urban Design International, 4:107-27.

Hillier, B. \& Leaman, A. 1973. The man-environment paradigm and its paradoxes. Architectural Design, 78(8): 507-11.

Hillier, B. \& Hanson, J. 1984. The Social Logic of Space. Cambridge: University Press.

Hillier, B. \& Iida, S. 2005. Network effects and psychological effects: a theory of urban movement. In: Nes, A. van ed. Proceedings of the 5th International Space Syntax Symposium. Delft: TU Delft University of Technology, 1: 553-64.

Hillier, B. \& Vaughan, L. 2007. The city as one thing. Progress in Planning, 67(3): 205-30.

Hillier, B. 2009 Spatial sustainability in cities: organic patterns and sustainable forms. In: Koch, D., Marcus, L. and Steen, J. ed. Proceedings of the 7th International Space Syntax Symposium. Stockholm: Royal Insitute of Technology (KTH), 1: k01.2-3.

Hillier, B., Yang, T. \& Turner, A. 2012. Normalising least angle choice in Depthmap and how it opens up new perspetives on the global and local analysis of the city space. Journal of Space Syntax, 3(2): 155-93. [Accessed: 1 July 2018]. Available at <http://www.journalofspacesyntax.org/>

Jacobs, B. A. 1993. Great Streets. Cambridge: The MIT Press.

Jukić, T. 1997. Strukturalne promjene rubnih dijelova grada - prilog proučavanju urbanističkog razvoja Zagreba. PhD thesis, Universitz

Lefebvre, H. 1991. \{original: 1974\}. The Production of Space. trans D.N. Smith, Blackwell, Malden M.A.; Oxford: Carlton.

Lennon, J.L., 2006. Cultural heritage management. In: M. Lockwood, G. Warboys, \& A. Kothari, eds. Protected areas management: a global guide. London: Earthscan, pp. 448-473.

Marić, T. \& Nataša, J. 2011. Petrinjska Street in Zagreb: Architectural and Urban Designs from the second half of the 18th to the late 20th Century. Prostor, 42: 
322-335. [Accessed 20 May 2017]. Available at:

$<$ https://hrcak.srce.hr/file/112243>

Marić, T., Bojanić Obad Šćitaroci, B. and Stiles, R. 2014. Recreating Human Scaled Streets. In: L. Cristea, P. Grecevicius, S. Nikčević, M. Meerovich, L. Altarelli, P.S. Letelier, D. Bershad, E. Lapidaki, M. Russeva eds. SGEM Conference on Arts, Performing Arts, Architecture and Design - Conference Proceedings. Sofia: SGEM International Multidisciplinary Scientific Conferences on Social Sciences and Arts, pp. 917-24.

Marić, T., Palaiologou, G., Griffiths, S., Bojanić Obad Šćitaroci, B. 2017. Gatewaypathway Heritage and Urban Growth - Zagreb case study. In: T. Heitor, M. Serra, J.P. Silva, M. Bacharel, L.C. da Silva eds. 11th International Space Syntax Symposium. [online] Lisbon: Instituto Superior Técnico, Departamento de Engenharia Civil, Arquitetura e Georrecursos, pp. 90.1-90.16 [Accessed 1 July 2018]. Available at: $<$ http://www.11ssslisbon.pt/docs/proceedings/papers/90.pdf >

Marishal, S. 2005. Streets and Patterns. London and New York: Spon Press Taylor \& Francis Group.

Milić, B. 1995. Razvoj grada kroz stoljeća II. Srednji vijek. Zagreb: Školska knjiga.

Milić, B. 2002. Razvoj grada kroz stoljeća III. Novo doba. Zagreb: Školska knjiga.

Mrak-Taritaš, A. 2008. Urban Development Plan - Zagreb as an Example of its Role and Significance. In: Prostor 16(2): 232-245. [Accessed 20 July 2018].

Available at: <https://hrcak.srce.hr/30701>

Palaiologou, G. 2015. High street transactions and interactions. In: Vaughan L ed. Suburban urbanities: suburbs and the life of the high street. London: UCL Press, pp. 175-203. [Accessed by: 1 July 2018.] Available at: https://doi.org/10.14324/111.9781910634134

Palaiologou, G. \& Griffiths, S. 2019. The Uses of Space Syntax Historical Research for Policy Development in Heritage Urbanism. In: Obad Šćitaroci, M., Bojanić Obad Šćitaroci, B., Mrđa, A. Cultural Urban Heritage - Development, Learning and Landscape Strategies. forthcoming

Pendlebury, J. 2013. Conservation values, the authorised heritage discourse and the conservation-planning assemblage. International Journal of Heritage Studies, 19(7): 709-727. [Accessed: 1 July 2018.] Available at: <https://doi.org/10.1080/13527258.2012.700282> 
Penn, A. 2003. Space syntax and spatial cognition: Or, why the axial line? Environment and Behavior, 35: 30-65

Pinho, P. \& Oliveira, V. 2009. Cartographic analysis in urban morphology. Environment and Planning B: Planning and Design, 36 (1): 107-27.

Rodwell, D. 2003. Sustainability and the holistic approach to the conservation of historic cities. Journal of Architectural Conservation 9(1): 58-73. [Accessed: 1 July 2018]. Available at: <https://doi.org/10.1080/13556207.2003.10785335 >

Schlüter, O. 1899. Bemerkungen zur Siedlungsgeogra phie. Geographische Zeitschrift, 5: 65-84.

Shpuza, E., 2014. Allometry in the syntax of street networks: evolution of Adriatic and Ionian coastal cities 1800- 2010. Environment and Planning B: Planning and Design, (Pion), 41(3): 450-71. [Accessed: 1 July 2018.] Available at: $<$ http://epb.sagepub.com/content/41/3/450.short>

Shpuza, E., 2009. Evolution of street networks in Adriatic and Ionian coastal cities 17692007. In: Proceedings of the Seventh International Space Syntax Symposium, Stockholm, 8-11 June 2009, [Accessed: 1 July 2018]. Available at: $<$ http://www.sss7.org/Proceedings/05\%20Spatial\%20Morphology\%20and\%20U rban\%20Growth/101_Shpuza.pdf>

Skalamera, Z., Pandzie, A. \& Bozienik, M. 1994. Zagreb na geodetsko-katastarskim zemljovidima i u zemljišnim knjigama, exhibition catalogue. Zagreb: Geodetski zavod za katastar i geodetske poslove.

Smith, L. 2006. Uses of Heritage. Abingdon: Routledge

Soini, K., Birkeland, I. 2014, Exploring the scientific discourse on cultural sustainability. Geoforum, 51: 213-223.

Taylor, K. 2009. Cultural landscapes and Asia: reconciling international and Southeast Asian regional values. Landscape Research, 34(1): 7-31.

Taylor, K. \& Lennon, J. 2011. Cultural landscapes: a bridge between culture and nature?. In: International Journal of Heritage Studies, 17:6, 537-554, [Accessed by: 1 July 2018.] Available at: DOI: 10.1080/13527258.2011.618246

Thomas, D. 2016. Placemaking: An Urban Design Methodology. Research in Planning and Urban Design. London and New York: Routledge

Timár, G., Molnár, G., Székely, B., Biszak, S., Varga, J., Jankó, A. (2006): Digitized maps of the Habsburg Empire - The map sheets of the second military survey 
and their georeferenced version. Arcanum, Budapest, 59 p. ISBN: 963-7374-337.

Törmä I., Griffiths S., Vaughan L.S. 2017. High street changeability: the effect of urban form on demolition, modification and use change in two South London suburbs. Urban Morphology, 21(1): 5-28.

Torre M. de la 2013. Values and heritage conservation. Heritage \& Society, 6(2): 155166. [Accessed by: 1 July 2018]. Available at: <https://doi.org/10.1179/2159032X13Z.00000000011>

Tunbridge, J.E. 1984. Whose Heritage To Conserve? Cross -Cultural Reflections On Political Dominance and Urban Heritage Conservation. Canadian Geographer, 26: $171-80$.

Turner, A. 2001. Depthmap: A program to perform visibility graph analysis. In: Peponis, J., Wineman, J. and Bafna, S. eds. Proceedings of the Third International Space Syntax Symposium. Atlanta: Georgia Institute of Technology, pp. 31.1-31.9.

Tweed C., Sutherland M. 2007. Built cultural heritage and sustainable urban development. Landscape and Urban Planning, 83(1): 62-9. [Accessed: 1 July 2018]. Available at: <https://doi.org/10.1016/j.landurbplan.2007.05.008 >

Vaughan L.S., Dhanani A., Griffiths S. 2013. Beyond the suburban high street cliché A study of adaptation to change in London's street network: 1880-2013. Journal of Space Syntax, 4(2): 221-41.

Veldpaus, L., Pereira Roders, A.Rm. \& Colenbrander, B.J.F. 2013. Urban heritage: putting the past into the future. The Historic Environment: Policy \& Practice, 4(1): 3-18. [Accessed: 1 July 2018]. Available at: <https://doi.org/10.1179/1756750513Z.00000000022>

Whyte, W. H. 1980. The Social Life of Small Urban Spaces. New York: Project for Public Spaces. 